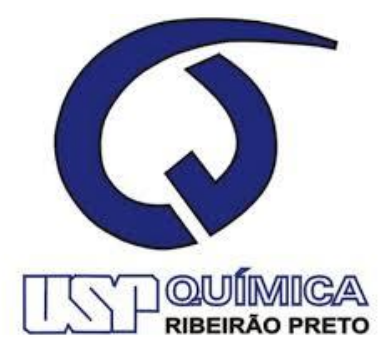

Universidade de São Paulo

Faculdade de Filosofia, Ciências e Letras de Ribeirão Preto

Departamento de Química

Programa de Pós Graduação em Química

Síntese e caracterização de nanocristais de LiYF 4 dopados com lantanídeos e suas aplicações em nanotermometria

João Marcos Gonçalves

Tese apresentada à Faculdade de Filosofia, Ciências e Letras de Ribeirão Preto da Universidade de São Paulo, como parte das exigências para a obtenção do título de Doutor em Ciências, Área: Química

Ribeirão Preto - SP

2020 


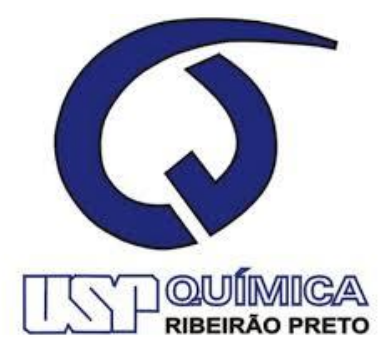

Universidade de São Paulo

Faculdade de Filosofia, Ciências e Letras de Ribeirão Preto

Departamento de Química

Programa de Pós Graduação em Química

Síntese e caracterização de nanocristais de $\mathrm{LiYF}_{4}$ dopados com lantanídeos e suas aplicações em nanotermometria

\title{
Versão resumida
}

\author{
João Marcos Gonçalves
}

Orientador: José Maurício Almeida Caiut

Co-orientador: Sidney José Lima Ribeiro

Tese apresentada à Faculdade de Filosofia, Ciências e Letras de Ribeirão Preto da Universidade de São Paulo, como parte das exigências para a obtenção do título de Doutor em Ciências, Área: Química

Ribeirão Preto - SP 


\section{FICHA CATALOGRÁFICA}

Gonçalves, João Marcos

Síntese e caracterização de nanocristais de $\mathrm{LiYF}_{4}$ dopados com lantanídeos e suas aplicações em nanotermometria.

Ribeirão Preto, 2020.

166 p. : il. ; $30 \mathrm{~cm}$

Tese de Doutorado, apresentada à Faculdade de Filosofia, Ciências e Letras de Ribeirão Preto/USP - Área de concentração: Química.

Orientadora: Caiut, José Maurício Almeida.

1. Termometria. 2. Luminescência. 3. Termômetros luminescentes. 4. Lantanídeos. 5. Nanopartículas luminescentes. 


\section{AGRADECIMENTOS}

Por todo o apoio durante todos esses anos, além de providenciar todo o amor todas as ferramentas que eu precisei durante essa caminhada, além de serem os maiores exemplos que eu tenho em minha vida, agradeço aos meus pais, Marco Antônio Gonçalves e Zilda Regina de Freitas Gonçalves. Também agradeço a minha irmã, Luana e sua mulher, Tatiane, que apesar da distância sempre me proporcionaram boas conversas, risadas e lembranças.

Agradeço também à minha namorada, Isabelle Floriano Esteves, por todo o apoio que precisei nessa difícil caminhada, pela paciência que demonstrou quando mais precisei, pelo grande amor e companheirismo inabalável nesse tempo. Obrigado pelas risadas, receitas e por fazer parte de tudo e de dividir e compartilhar seus sonhos comigo, agradeço por ter mudado minha visão do mundo e me resgatado para momentos mais felizes e mais leves.

Aos orientadores dessa tese, prof. Caiut e prof. Sidney, além da profa. Rute, por mostrarem o caminho da boa ciência, compartilhar comigo seus conhecimentos e ajudarem em todos os momentos oportunos, seja no âmbito profissional ou pessoal.

Aos meus companheiros de laboratório, Douglas, Roberta, Eloísa, Euzane, Francisco, Luan, Fernandinho, André, Larissa Justino, Caroline, Ana, Letícia, Izabela, Larissa e Renata. Todos vocês tiveram um enorme impacto em minha vida pessoal e profissional, por mais breve que tenhamos tido contato.

Aos companheiros do Phantom-G, em Aveiro. Apesar da breve estadia, foi um prazer imenso conhecê-los e trabalhar com vocês. Em especial, agradeço à profa. Rute pela oportunidade, à Rita Bastos e Alexandre Botas por toda a ajuda e aos amigos Miguel, Justina, Talita, Rodolfo, Zeca, Thiago, Albano, Sofia, Fernando e Joana, sem esquecer do prof. Luis Carlos e prof. Carlos Brites.

Aos laboratórios parceiros MaterLum, Materiais Fotônicos e Sol-Gel pela parceria com equipamentos e também pelas discussões produtivas, em especial ao Fábio Caixeta por toda a ajuda em Aveiro.

E, por fim, aos meus amigos de graduação do grupo da Tartariiga e meus amigos de Overwatch pela distração tão necessária e pelas risadas. Em especial ao Alison por fazer parte desses dois grupos. 
"You need not to climb mountain tops

You need not to cross the sea

You need not to find a cure For everything that makes you weak

You need not to reach for the stars When life becomes so dark And when the wind Does blow against the grain You must follow your heart"

Dallas Green 


\section{RESUMO}

GONÇALVES, João Marcos. Síntese e caracterização de nanocristais de $\mathrm{LiYF}_{4}$ dopados com lantanídeos e suas aplicações em nanotermometria. 2020. 166 p. Tese (Doutorado em Química) - Faculdade de Filosofia, Ciências e Letras, Universidade de São Paulo, Ribeirão Preto, 2020.

A temperatura é um fator chave para a descrição de diversos fenômenos e sistemas, e a miniaturização de diversos tipos de tecnologia torna necessária sua aferição em escala nanométrica. As atuais técnicas de medição de temperatura possuem a limitação espacial à escala de poucos micrômetros, por esse motivo nanopartículas têm sido abordadas para atingir a leitura de temperatura até a escala nanométrica. Íons lantanídeos possuem estados excitados termicamente acoplados, ou seja, a população relativa destes níveis está diretamente ligada à temperatura em que o sistema se encontra, fazendo com que sejam ideais para termômetros. A matriz utilizada neste trabalho, o $\mathrm{LiYF}_{4}$, é conhecida por possuir uma baixa energia de fônons que, associada à dopagem com íons lantanídeos, é capaz de gerar propriedades espectroscópicas úteis para a termometria. Neste trabalho foram utilizadas duas dopagens distintas; a primeira com $\mathrm{Eu}^{3+}$, cuja emissão oriunda dos estados excitados ${ }^{5} D_{0}$ e ${ }^{5} D_{1}$ são observáveis nesta matriz e possuem dependência com a temperatura, e a segunda com o par $\mathrm{Yb}^{3+} / \mathrm{Er}^{3+}$ que apresentam emissão na região do visível a partir da excitação no infravermelho. As amostras contendo $\mathrm{Eu}^{3+}$ mostraram-se excelentes termômetros luminescentes no estado sólido sob excitação em $392 \mathrm{~nm}$, com sensibilidade relativa $2,789 \pm 0,001 \% \cdot \mathrm{K}^{-1}$ a $300 \mathrm{~K}$ e incerteza da temperatura de 0,12 K. Já as nanopartículas dopadas com o par $\mathrm{Yb}^{3+} / \mathrm{Er}^{3+}$ se mostraram termômetros tanto em dispersões hidrofóbicas quanto em água, com sensibilidade relativa da ordem de $1,24 \% \cdot \mathrm{K}^{-1}$ a $300 \mathrm{~K}$, a depender da concentração de dopantes no sistema, ao analisar a incerteza da temperatura, melhorias no sistema ainda são necessárias. Foi proposta e estudado a inclusão de nanopartículas de ouro a superfície dos fluoretos, com uma possível rota de geração de calor localizada, visando fins de terapia fototérmica, entretanto tal aquecimento não foi observado.

Palavras-chave: Termometria. Luminescência. Termômetros luminescentes. Lantanídeos. Nanopartículas luminescentes. 


\section{ABSTRACT}

GONÇALVES, João Marcos. Synthesis and characterization of lanthanide-doped LiYF $_{4}$ nanocrystals and their nanothermometry applications. 2020. 166 p. Thesis (Doctorate in Chemistry) - Faculdade de Filosofia, Ciências e Letras, Universidade de São Paulo, Ribeirão Preto, 2020.

Temperature is a key fator to describe several phenomena and systems, and miniaturization of several types of technology makes its measurement needed in the nanoscale. Current techniques to measure the temperature have a scale limitation of a few micrometers, for this reason, nanoparticles have been explored to achieve temperature reading in the nanoscale. Lanthanide ions have thermally coupled excited states, i.e. their population is directly dependent of the temperature in which the system is immersed, making them ideal for thermometers. The host used in this thesis, $\mathrm{LiYF}_{4}$, is known to possess low phonon energy which, associated with lanthanide doping, is capable of producing useful spectroscopic properties for thermometry. In this work, two different dopings were used; the first being $\mathrm{Eu}^{3+}$, in which emissions from the ${ }^{5} \mathrm{D}_{1}$ and ${ }^{5} \mathrm{D}_{0}$ are observed in this host and have temperature dependency, and the second the $\mathrm{Yb}^{3+} / \mathrm{Er}^{3+}$ pair which present visible emission through infrared excitation which are temperature dependent. The samples containing Eu3+ showed great temperature readout in solid state under $392 \mathrm{~nm}$ excitation, with relative thermal sensitivity of 2.789 $\pm 0.001 \% \cdot \mathrm{K}^{-1}$ at $300 \mathrm{~K}$ and temperature uncertainty of $0.12 \mathrm{~K}$. The $\mathrm{Yb}^{3+} / \mathrm{Er}^{3+}$ codoped particles also showed temperature readout in water and organic solvent dispersions, with thermal sensitivity in the $1.24 \% \cdot \mathrm{K}^{-1}$ at $300 \mathrm{~K}$ range, depending on the dopant concentration and high temperature uncertainty, which shows that this systems needs improvement. Also, it was proposed and studied that the inclusion of gold nanoparticles at the surface of the fluoride particles could be a way to generate localized heating, which was not observed.

Keywords: Thermometry. Luminescence. Luminescent thermometers. Lanthanides. Luminescent nanoparticles. 


\section{LISTA DE FIGURAS}

Figura 1 - Esquema de níveis de energia mostrando a excitação de um material para seu estado excitado e possíveis decaimentos, onde $A$ é o estado fundamental, $A^{*}$ o estado excitado e $A^{* \prime}$ um estado excitado intermediário. A seta preta indica a absorção de energia, as setas ondulada perdas de energia não radiativa e as setas azuis a emissão de energia (luminescência).

Figura 2 - Representação esquemática de um material que contém um sensibilizador e um ativador e dos mecanismos possíveis de emissão, na qual uma delas a excitação e emissão diretamente pela espécie ativadora e a outra em que a excitação ocorre em um sensibilizador que transfere energia para o ativador. 21

Figura 3 - Distribuição radia quadrátical das funções de onda hidrogenóides dos orbitais $4 f, 5 d$ e 6 s do íon $\mathrm{Gd}^{+}$. 25

Figura 4 - Quebras de degenerescência observadas em lantanídeos para a repulsão intereletrônica, acoplamento spin-órbita e campo cristalino com suas respectivas energias de desdobramento observadas.

Figura 5 - Diagrama de níveis de energia para os íons lantanídeos trivalentes .28 Figura 6 - Figura esquemática do mecanismo do efeito antena, onde hv indica o fóton incidente, hv' indica o fóton emitido, A o estado fundamental do cromóforo que funciona como antena, $A^{*}$ seu estado excitado, Ln o estado fundamental do íon lantanídeo, $\mathrm{Ln}^{*}$ seu estado excitado, a seta preta representa a absorção do fóton incidente, a seta vermelha a emissão do fóton hv' e a seta verde a transferência de energia entre os estados excitados da antena e do lantanídeo.

Figura 7 - Mecanismos de conversão ascendente de energia por transferência de energia e absorção do estado excitado. 33

Figura 8 - Diagrama de níveis de energia dos íons $\mathrm{Yb}^{3+}$ e $\mathrm{Er}^{3+}$ e mecanismos de conversão ascendente de materiais dopados com esses lantanídeos. .37

Figura 9 - Diagrama de níveis de energia do $\mathrm{Eu}^{3+}$, evidenciando a diferença de energia entre os estados excitados ${ }^{5} \mathrm{D}_{0}$ e ${ }^{5} \mathrm{D}_{1}$, e do $\mathrm{Er}^{3+}$, evidenciando a diferença de energia dos níveis ${ }^{2} \mathrm{H}_{11 / 2} \mathrm{e}^{4} \mathrm{~S}_{3 / 2}$.

Figura 10 - Diagrama de níveis de energia hipotético para um material que servirá de termômetro.

Figura 11 - Geração de uma oscilação na nuvem eletrônica de uma nanopartícula de ouro por meio da incidência de radiação eletromagnética. 
Figura 12 - Desenho esquemático do experimento de geração de plasma de $\mathrm{He}$ a partir de um gerador de baixa frequência (LFG), um amplificador de potência e um transformador gerando uma descarga no eletrodo. Esta descarga será responsável pela geração do plasma de He na seringa...... .45 


\section{LISTA DE TABELAS}

Tabela 1 - Diferentes tipos de luminescência definidas a partir do seu tipo de excitação 20

Tabela 2 - Distribuição eletrônica dos lantanídeos em seus estados de oxidação 0 e +3 , e quando há ocorrência, +2 e +4 .24

Tabela 3 - Número de componentes dos subníveis Stark observados em espectros de emissão do íon $\mathrm{Eu}^{3+}$ de acordo com o grupo de ponto em que ele se encontra........30 Tabela 4 - Energias de fônon para materiais comumente utilizados para conversão ascendente de energia 
Sumário

Capítulo 1 - Introdução 17

1.1. Luminescência

1.2. Lantanídeos 22

1.3. $\mathrm{O}$ íon $\mathrm{Eu}^{3+}$ 30

1.4. Conversão ascendente de energia 31

1.5. Temperatura e termômetros luminescentes 38

1.6. Nanopartículas de ouro 43

1.7. Objetivos 47

1.8. Referências 48

Capítulo 2 - Caracterização estrutural dos nanocristais de $\mathrm{LiYF}_{4}$ e sua modificação com cisteína 60

2.1. Conclusão parcial 61

Capítulo 3 - Propriedades espectroscópicas das nanopartículas de $\mathrm{LiYF}_{4}$ dopadas com lantanídeos 63

3.1. Conclusões parciais 64

Capítulo 4 - Nanopartículas de $\mathrm{LiYF}_{4}$ como termômetros 66

4.1. Conclusões parciais 67

Capítulo 5 - Modificação das nanopartículas de $\mathrm{LiYF}_{4}$ com nanopartículas de ouro e estudo de efeito fototérmico 69

5.1. Conclusões parciais 70

$\diamond \quad$ Conclusão geral 71

$\diamond$ Perspectivas 75 
Capítulo 1 - Introdução 


\section{INTRODUÇÃO}

\subsection{Luminescência}

Segundo a International Union of Pure and Applied Chemistry (IUPAC), a definição de luminescência é a emissão espontânea de radiação de uma espécie no estado excitado que não esteja em equilíbrio térmico com seu ambiente (1). Uma definição mais usual é a descrita por Blasse para material luminescente, que é o material que converte certos tipos de radiação em radiação eletromagnética, excluindo a emissão que acontece pela radiação do corpo negro (2).

De maneira geral, podemos definir a luminescência como a emissão de luz feita por um material que absorveu alguma forma de energia; a Figura 1 mostra um esquema de níveis de energia ilustrando esse conceito. Em primeiro lugar, o material absorve uma quantidade de energia suficiente para promove-lo do estado fundamental para o estado excitado (seta preta, Figura 1); em seguida, ele pode retornar ao estado fundamental de duas maneiras: a primeira, sem popular um estado intermediário, decaindo diretamente do estado excitado $A^{*}$ para o estado fundamental A de maneira não radiativa na forma de calor, por exemplo, ou ainda de maneira radiativa; a segunda, populando um nível intermediário $A^{* \prime}$ perdendo energia de maneira não radiativa (seta ondulada, Figura 1 ) em seguida emitindo radiação (seta azul, Figura 1). Os processos pelos quais há emissão de energia (decaimentos radiativos) chamamos luminescência (2). 
Figura 1 - Esquema de níveis de energia mostrando a excitação de um material para seu estado excitado e possíveis decaimentos, onde $A$ é o estado fundamental, $A^{*}$ o estado excitado e $A^{* \prime}$ um estado excitado intermediário. A seta preta indica a absorção de energia, as setas ondulada perdas de energia não radiativa e as setas azuis a emissão de energia (luminescência).

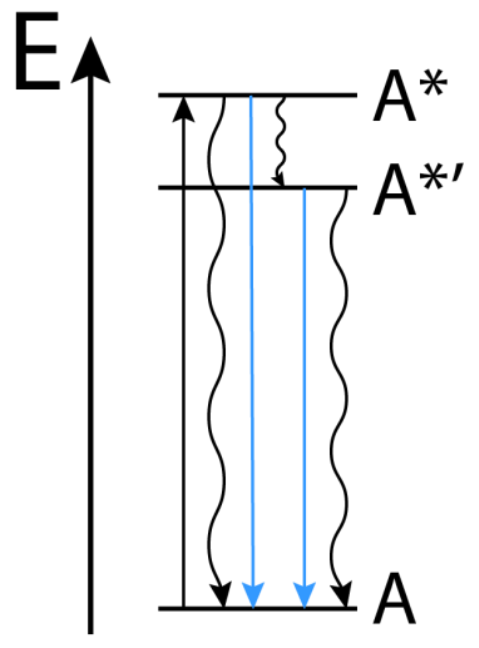

Fonte: 0 autor.

Neste diagrama de níveis de energia, percebe-se que a energia emitida é menor do que a energia absorvida, portanto, ao analisarmos o espectro de excitação e emissão dos materiais luminescentes, a excitação se dá em menores comprimentos de onda (maior energia), enquanto a emissão se dá em maiores comprimentos de onda (menor energia), como mostrado na Figura 1, e se dá o nome de downshifting (3) e este processo será explorado nesse trabalho para o íon $\mathrm{Eu}^{3+}$. Para o par de íons $\mathrm{Yb}^{3+} / \mathrm{Er}^{3+}$ será explorado um outro processo, chamado conversão ascendente de energia (ou upconversion), descrito em mais detalhes na seção 1.4. A conversão ascendente é definida como a emissão de um fóton a partir da absorção de dois ou mais fótons (4).

O tipo de excitação do estado fundamental para o estado excitado pode variar; alguns exemplos são a quimiluminescência (excitação a partir de reações químicas), radioluminescência (excitação a partir de radiação ionizante), sonoluminescência (excitação por ondas acústicas), triboluminescência (excitação por atrito) e fotoluminescência (excitação a partir de radiação eletromagnética) (1). A Tabela 1 apresenta um exemplo para cada tipo de excitação citada no texto. O foco deste trabalho se dá na fotoluminescência, portanto, será considerada apenas a luz como fonte de excitação. 
Tabela 1 - Diferentes tipos de luminescência definidas a partir do seu tipo de excitação

\begin{tabular}{cccc}
\hline Tipo de excitação & Nome & Exemplo & Referência \\
\hline Reações químicas & Quimiluminescência & Luminol & $(5)$ \\
Radiação ionizante & Radioluminescência & $\mathrm{CaWO}_{4}$ & $(6)$ \\
Ondas acústicas & Sonoluminescência & $\mathrm{Fe}(\mathrm{CO})_{5}$ & $(7)$ \\
Atrito & Triboluminescência & Sacarose & $(8)$ \\
Radiação eletromagnética & Fotoluminescência & LiYF4:Eu $^{3+}$ & $(9)$ \\
\hline
\end{tabular}

Fonte: 0 autor.

Diferentes tipos de materiais exibem fotoluminescência, como por exemplo, moléculas orgânicas, quantum dots, complexos de lantanídeos e materiais inorgânicos dopados com lantanídeos, cujos exemplos serão explorados a seguir.

A Rodamina 800 é uma molécula orgânica que, excitada em 633 nm, apresenta uma banda de emissão de luz com comprimento de onda máximo $708 \mathrm{~nm}$ em metanol (10). Um outro exemplo de fotoluminescência em moléculas orgânica são as proteínas fluorescentes verdes, ou do inglês, green fluorescente proteins (GFPs), cuja variante extraída da água viva Aequorea victoria possui uma banda de emissão centrada em 508 nm quando excitada em 395 nm (11). Os quantum dots são nanopartículas de materiais semicondutores, cujo espectro de emissão é diretamente influenciado por seu tamanho, como por exemplo materiais à base de $\mathrm{CdS}$, que possui emissões de 355 à 490 nm com seu diâmetro variando entre 1,9 à 6,7 nm (12).

Lantanídeos podem exibir fotoluminescência tanto em complexos quanto quando presentes como dopantes em materiais inorgânicos. Um exemplo de complexo de lantanídeo que apresenta fotoluminescência é o tris(1-fenil-1,3butanodiona)európio(III), que apresenta emissão típica do íon $\mathrm{Eu}^{3+}$ com máximo de emissão em $613 \mathrm{~nm}$ quando excitado em $367 \mathrm{~nm}$ (13). O íon európio trivalente também pode estar presente como dopante em materiais inorgânicos, como no caso do LiYF $_{4}$, e apresentar fotoluminescência com emissão em 613 nm e excitação em $395 \mathrm{~nm}(9,14)$.

Cada um dos exemplos de materiais fotoluminescentes dados possui suas particularidades quanto ao mecanismo envolvido em sua emissão, entretanto será 
detalhado apenas o último caso, de materiais inorgânicos dopados com lantanídeos, já que ele representa o material estudado nesta tese.

A excitação por fótons pode ocorrer de duas maneiras nesse tipo de material: diretamente na espécie que emite energia, como no já citado caso do $\mathrm{LiYF}_{4}$ dopado com íons $\mathrm{Eu}^{3+}(9,14)$ ou primeiramente em um sensibilizador, que transfere energia para a espécie emissora (chamada ativadora) $(2,15)$, como é o caso do $\mathrm{NaYF}_{4}$ dopado com íons $\mathrm{Yb}^{3+}$ e $\mathrm{Er}^{3+}$, no qual o íon $\mathrm{Yb}^{3+}$ atua como sensibilizador do íon $\mathrm{Er}^{3+}$ no mecanismo de luminescência via conversão ascendente de energia (16). O uso de sensibilizadores está associada à limitações do ativador, como sua baixa absorção (15). Um esquema mostrando como pode ocorrer a excitação para que haja emissão de energia está apresentado no Figura 2, onde as setas pontilhadas representam a transferência de energia.

Figura 2 - Representação esquemática de um material que contém um sensibilizador e um ativador e dos mecanismos possíveis de emissão, na qual uma delas a excitação e emissão diretamente pela espécie ativadora e a outra em que a excitação ocorre em um sensibilizador que transfere energia para $o$ ativador.

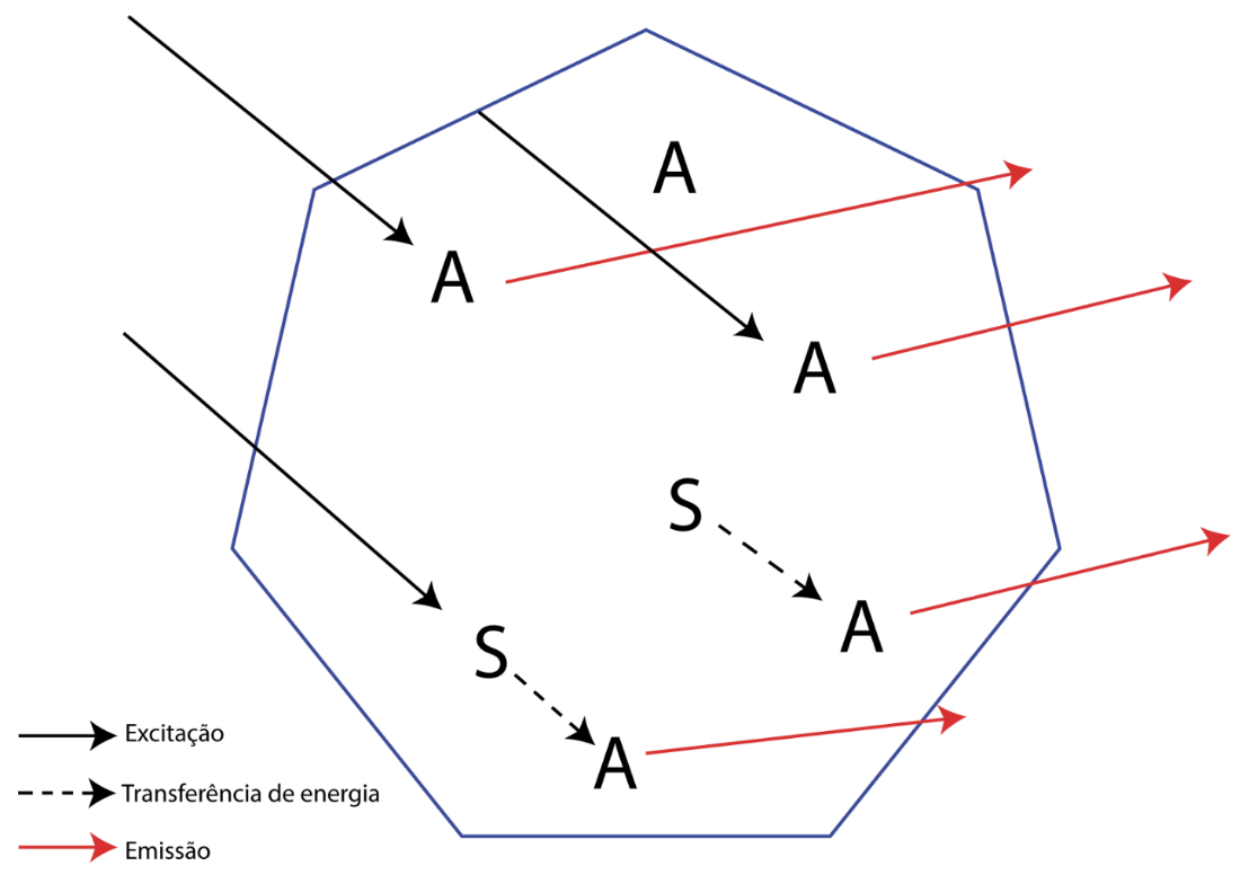

Fonte: adaptado de (2).

Os processos de transferências de energia podem ter uma grande importância em materiais como o $\mathrm{NaYF}_{4}$ dopado com $\mathrm{Yb} / \mathrm{Er}$ ou $\mathrm{Yb} / \mathrm{Tm}$, já que o sensibilizador está presente no material para aumentar a eficiência de emissão, uma vez que o $\mathrm{Yb}^{3+}$ absorve energia de forma mais eficiente que os outros lantanídeos $(4,16)$. 
Para que ocorra a transferência de energia, duas condições precisam ser atendidas: o sensibilizador e o ativador necessitam ter uma sobreposição energética de seus níveis excitados e precisam estar em uma distância pequena suficiente para interagirem entre si (2). A distância dependerá do tipo de interação: quando as transições possuem caráter de dipolo elétrico, a interação é do tipo dipolo-dipolo, e a probabilidade da transferência de energia é dada pela equação 1, e é chamada de transferência de energia de Förster $(17,18)$; também é possível a interação dipoloquadrupolo, que é chamada de transferência de energia de Dexter, cuja probabilidade de transferência é dada pela equação 2 (17-19):

$$
\begin{aligned}
& P_{d d}(R)=\frac{A}{R^{6}} \int \frac{f_{S}(E) f_{A}(E)}{E^{4}} d E \\
& P_{d q}(R)=\frac{B}{R^{8}} \int \frac{f_{S}(E) f_{A}(E)}{E^{8}} d E
\end{aligned}
$$

Onde $\mathrm{P}$ é a probabilidade de transferência de energia, A e B são termos que dependem dos tempos de vida radiativos do sensibilizador e ativador, do índice de refração do material e da seção de choque de absorção do ativador, $\mathrm{R}$ a distância entre essas espécies, $f_{S}(E) f_{A}(E)$ representa sobreposição espectral entre a emissão do sensibilizador e a absorção do ativador e $E$ é o valor de energia onde ocorre a máxima sobreposição $f_{S}(E) f_{A}(E)(2,17)$. Nota-se que a distância entre o sensibilizador e ativador é inversamente proporcional à probabilidade da transferência de energia, portanto, as espécies devem estar próximas uma da outra.

Nesta tese, serão destacados alguns materiais que possuem como base a fotoluminescência de íons lantanídeos; eles possuem características únicas, como a largura de seus picos de emissão, baixa influência do ambiente de coordenação e elevados tempos de vida do estado excitado, que podem ser exploradas para diversas aplicações tecnológicas e, portanto, serão discutidos na seção posterior.

\subsection{Lantanídeos}

A descoberta dos lantanídeos se deu na Escandinávia, iniciando-se com Johann Gadolin em 1794 com a obtenção da ítria (uma mistura de óxidos de ítrio, itérbio e érbio) e com o último lantanídeo a ser separado sendo o promécio, em 1948 $(20,21)$. A dificuldade da separação dos lantanídeos é o motivo principal para que 
tantos anos separassem sua primeira obtenção de sua separação, uma vez que, geralmente, eles são encontrados com o mesmo número de oxidação $(+3)$ e raios atômicos bastante próximos, necessitando de métodos laboriosos para completa separação $(20,21)$. Esses métodos podem ser separados em três: separação química, métodos de troca iônica e extração com solvente.

A separação química pode ser feita tanto por precipitação de sais insolúveis quanto na cristalização. A precipitação implica na mistura de dois ou mais sais solúveis que produzirão outro, menos solúvel, como no caso da precipitação como hidróxidos, por exemplo. Já na cristalização um sal é obtivo a partir de uma solução concentrada que, a partir diminuição do volume do solvente ou variação da temperatura, ocorre a cristalização desse sal que pode ser separado (22). Há também a possibilidade de utilizar-se de estados de oxidação menos comuns, seguidos de precipitação ou cristalização $(20,21)$.

A troca iônica é um método cromatográfico que permite separar os lantanídeos de acordo com sua afinidade em uma resina de troca iônica (fase estacionária), que está relacionado tanto com o tamanho do íon hidratado quanto de sua carga. Como os lantanídeos possuem características similares entre si, sendo necessário ainda um tratamento da fase estacionária com agentes complexantes, a fim de realizar-se a separação ainda de acordo com a estabilidade dos complexos (22).

Por fim, a extração com solventes é um método baseado no coeficiente de partição dos lantanídeos em uma mistura de solventes imiscíveis, isto é, na migração dos lantanídeos de uma fase aquosa para uma fase orgânica. Por exemplo, utilizandose fosfato de tributila (TBP) e ácido nítrico, é possível realizar a separação dos lantanídeos, bastando variar a concentração do ácido nítrico, que fará com que diferentes lantanídeos estejam presentes na fase orgânica, a partir da formação de diferentes complexos com o TBP (22).

Os lantanídeos são os elementos químicos que se encontram entre o lantânio e o lutécio na tabela periódica, e são caracterizados pela sucessiva ocupação de elétrons na camada $4 f(20,23)$. Como dito anteriormente, o número de oxidação mais comum e estável para os lantanídeos é o +3 , embora os estados de oxidação +2 e +4 também sejam observados $(20,21,23)$. A Tabela 2 apresenta a configuração eletrônica 
dos lantanídeos em seus estados de oxidação 0 e +3, e, quando observados, $0+2$ e +4 .

Tabela 2 - Distribuição eletrônica dos lantanídeos em seus estados de oxidação 0 e +3 , e quando há ocorrência, +2 e +4

\begin{tabular}{|c|c|c|c|c|}
\hline & $\overline{0}$ & +2 & +3 & +4 \\
\hline La $(Z=57)$ & {$[\mathrm{Xe}] 5 d^{1} 6 s^{2}$} & - & {$[\mathrm{Xe}]$} & - \\
\hline $\mathrm{Ce}(Z=58)$ & {$[X e] 4 f^{1} 5 d^{1} 6 s^{2}$} & - & {$[\mathrm{Xe}] 4 \mathrm{f}^{1}$} & {$[\mathrm{Xe}]$} \\
\hline $\operatorname{Pr}(Z=59)$ & {$[X e] 4 f^{3} 6 s^{2}$} & - & {$[\mathrm{Xe}] 4 \mathrm{f}^{2}$} & {$[\mathrm{Xe}] 4 \mathrm{f}^{1}$} \\
\hline $\mathrm{Nd}(Z=60)$ & {$[X e] 4 f^{4} 6 s^{2}$} & {$[\mathrm{Xe}] 4 \mathrm{f}^{4}$} & {$[\mathrm{Xe}] 4 \mathrm{f}^{3}$} & {$[\mathrm{Xe}] 4 \mathrm{f}^{2}$} \\
\hline $\operatorname{Pm}(Z=61)$ & {$[\mathrm{Xe}] 4 \mathrm{f}^{5} 6 \mathrm{~s}^{2}$} & - & {$[\mathrm{Xe}] 4 \mathrm{f}^{4}$} & - \\
\hline $\operatorname{Sm}(Z=62)$ & {$[\mathrm{Xe}] 4 f^{6} 6 s^{2}$} & {$[\mathrm{Xe}] 4 \mathrm{f}^{6}$} & {$[\mathrm{Xe}] 4 \mathrm{f}^{5}$} & - \\
\hline $\mathrm{Eu}(Z=63)$ & {$[\mathrm{Xe}] 4 \mathrm{f}^{7} 6 \mathrm{~s}^{2}$} & {$[\mathrm{Xe}] 4 \mathrm{f}^{7}$} & {$[\mathrm{Xe}] 4 \mathrm{f}^{6}$} & \\
\hline $\mathrm{Gd}(Z=64)$ & {$[X e] 4 f^{7} 5 d^{1} 6 s^{2}$} & - & {$[\mathrm{Xe}] 4 \mathrm{f}^{7}$} & - \\
\hline $\mathrm{Tb}(Z=65)$ & {$[\mathrm{Xe}] 4 f^{9} 6 s^{2}$} & & {$[\mathrm{Xe}] 4 \mathrm{f}^{8}$} & {$[\mathrm{Xe}] 4 \mathrm{f}^{7}$} \\
\hline Dy $(Z=66)$ & {$[X e] 4 f^{10} 6 s^{2}$} & {$[\mathrm{Xe}] 4 \mathrm{f}^{10}$} & {$[\mathrm{Xe}] 4 \mathrm{f}^{9}$} & {$[\mathrm{Xe}] 4 \mathrm{f}^{8}$} \\
\hline Ho $(Z=67)$ & {$[X e] 4 f^{11} 6 s^{2}$} & - & {$[\mathrm{Xe}] 4 \mathrm{f}^{10}$} & - \\
\hline $\operatorname{Er}(Z=68)$ & {$[X e] 4 f^{12} 6 s^{2}$} & - & {$[\mathrm{Xe}] 4 \mathrm{f}^{11}$} & - \\
\hline $\operatorname{Tm}(Z=69)$ & {$[X e] 4 f^{13} 6 s^{2}$} & {$[\mathrm{Xe}] 4 \mathrm{f}^{13}$} & {$[\mathrm{Xe}] 4 \mathrm{f}^{12}$} & - \\
\hline $\mathrm{Yb}(\mathrm{Z}=70)$ & {$[X e] 4 f^{14} 6 s^{2}$} & {$[\mathrm{Xe}] 4 \mathrm{f}^{14}$} & {$[\mathrm{Xe}] 4 \mathrm{f}^{13}$} & - \\
\hline $\operatorname{Lu}(Z=71)$ & {$[\mathrm{Xe}] 4 \mathrm{f}^{14} 5 \mathrm{~d}^{1} 6 \mathrm{~s}^{2}$} & - & {$[\mathrm{Xe}] 4 \mathrm{f}^{14}$} & - \\
\hline
\end{tabular}

Adaptado de (20).

Em um átomo hidrogenóide, calcula-se a energia dos níveis de um átomo, utiliza-se a equação de Schödinger: 


$$
\hat{\mathrm{H}} \Psi=E \Psi
$$

onde $\hat{H}$ é o operador Hamiltoniano, em que estão incluídos os operadores de energia cinética e potencial para a função de onda (24). A função de onda que descrevem o iésimo elétron na aproximação orbital pode ser representada da seguinte forma:

$$
\Psi_{i}(r, \theta, \Phi)=R_{i}(r) Y_{i}(\theta, \Phi)
$$

Onde $R_{i}(r)$ representa a função de onda radial do i-ésimo elétron, e $Y_{i}(\theta, \Phi)$ a função de onda angular dos orbitais hidrogenóides utilizando coordenadas polares (24).

Uma característica importante dos orbitais $f$, que será crucial para as propriedades espectroscópicas é que eles são mais internos do que os orbitais $5 d$ e 6s presentes nos lantanídeos. Isso pode ser facilmente observado na distribuição radial de densidade para os elétrons nas camadas $4 \mathrm{f}, 5 \mathrm{~d}$ e $6 \mathrm{~s}$ em função da distância do núcleo (Figura 3) (25). Este fato fará com que os elétrons das camadas $4 f$ sejam blindados do exterior pelos $5 \mathrm{~d}$, acarretando em uma relativa insensibilidade da emissão dos lantanídeos ao ambiente químico, como será explorado a seguir.

Figura 3 - Distribuição radia quadrátical das funções de onda hidrogenóides dos orbitais $4 f, 5 d$ e $6 s$ do íon $\mathrm{Gd}^{+}$.

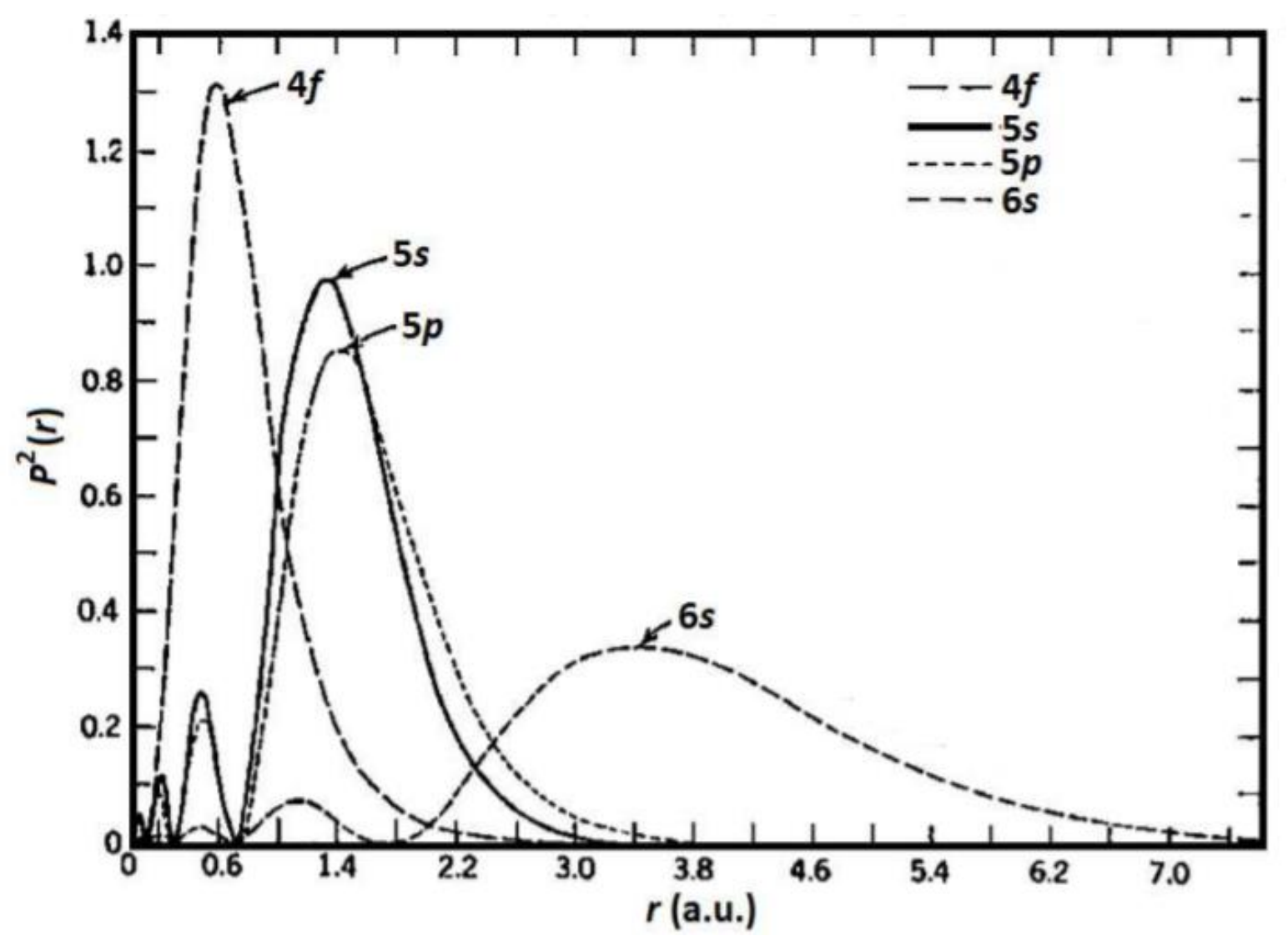


Soluções analíticas exatas para a equação 4 só são obtidas para átomos hidrogenóides, ou seja, um átomo que possui apenas um elétron (24). Para átomos multieletrônicos consideram-se aproximações para o cálculo dos níveis de energia, em que uma delas é a Teoria das Perturbações, na qual a função inicial é o produto simples de orbitais hidrogenóides para os elétrons do sistema atômico polieletrônico (27). O lantanídeo, então, é tratado como um sistema atômico isolado que posteriormente é perturbado por um campo cristalino externo, resultando em um hamiltoniano com o formato dado pela equação 5.

$$
H=H_{R E}+H_{S O}+H_{C C}
$$

onde $H_{R E}$ é a perturbação da repulsão eletrônica entre os elétrons, Hso é o acoplamento spin-órbita e Hcc é a perturbação causada pelo campo cristalino (21).

A primeira perturbação a ser considerada é a repulsão coulômbica ( $\left.H_{\mathrm{RE}}\right)$ entre os elétrons que estão nos subníveis $4 \mathrm{f}$, que quebra a degenerescência da configuração eletrônica em termos espectroscópicos do tipo ${ }^{2 \mathrm{~S}+1} \mathrm{~L}$, onde $\mathrm{S}$ é a soma dos momentos angulares de spin dos elétrons, $L$ a soma dos momentos angulares orbitais e cujo desdobramento está na ordem dos $10000 \mathrm{~cm}^{-1}(21,28)$.

A segunda perturbação considerada é o acoplamento spin-órbita (Hso) que leva em conta a interação entre o momento angular da órbita do elétron e seu momento angular de spin, em que cada um dos termos espectroscópicos será desdobrado em níveis ${ }^{2 S+1} \mathrm{LJ}$, onde $\mathrm{J}$ é a soma de $\mathrm{S}$ e $\mathrm{L}$, com um desdobramento da ordem de 1000 $\mathrm{cm}^{-1}(21,28)$.

A última perturbação a ser considerada neste trabalho é a perturbação causada pelo ambiente externo, ou desdobramento do campo cristalino $(\mathrm{Hcc})$, cujo desdobramento está na ordem de apenas $100 \mathrm{~cm}^{-1}$, dando à esses elementos características de emissão atômicas $(20,21)$. Com a influência do campo cristalino (ambiente externo), esses níveis de energia podem ser desdobrados em $2 \mathrm{~J}+1$, que também são chamados subníveis Stark $(2,29)$. A Figura 4 representa como uma dessas perturbações, juntamente com a ordem de grandeza em que quebram a degenerescência dos níveis de energia. O número de subníveis Stark observados em 
um espectro de emissão está diretamente relacionado ao grupo de ponto em que o lantanídeo se encontra (20).

Figura 4 - Quebras de degenerescência observadas em lantanídeos para a repulsão intereletrônica, acoplamento spin-órbita e campo cristalino com suas respectivas energias de desdobramento observadas.

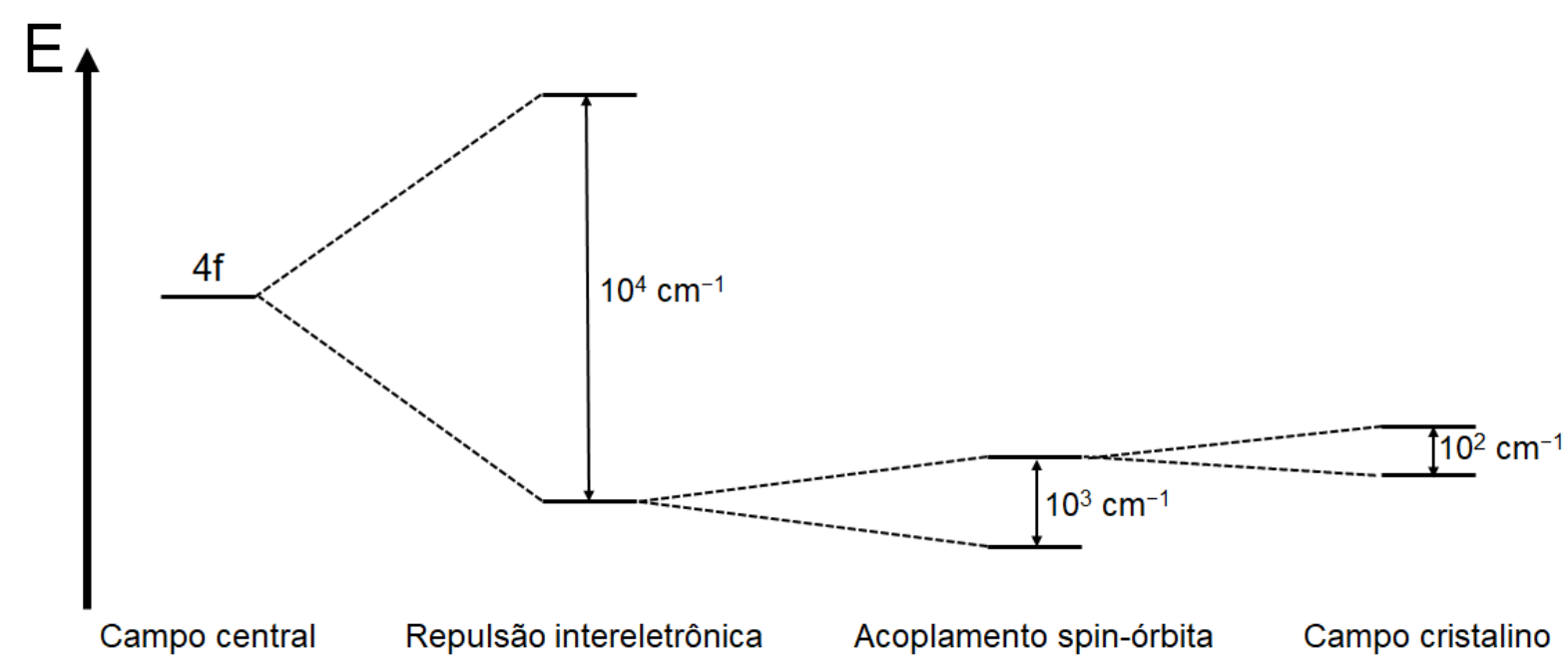

Adaptado de (29).

Desta forma, nota-se que o ambiente de coordenação em que o lantanídeo está inserido tem pouca influência em suas propriedades espectroscópicas. Esta pequena influência é representada pelos diagramas de níveis de energia para os lantanídeos, destacando-se os trabalhos de Dieke (30) e Carnall (31). Na Figura 5 está apresentado o diagrama de níveis de energia de Carnall. 
Figura 5 - Diagrama de níveis de energia para os íons lantanídeos trivalentes.

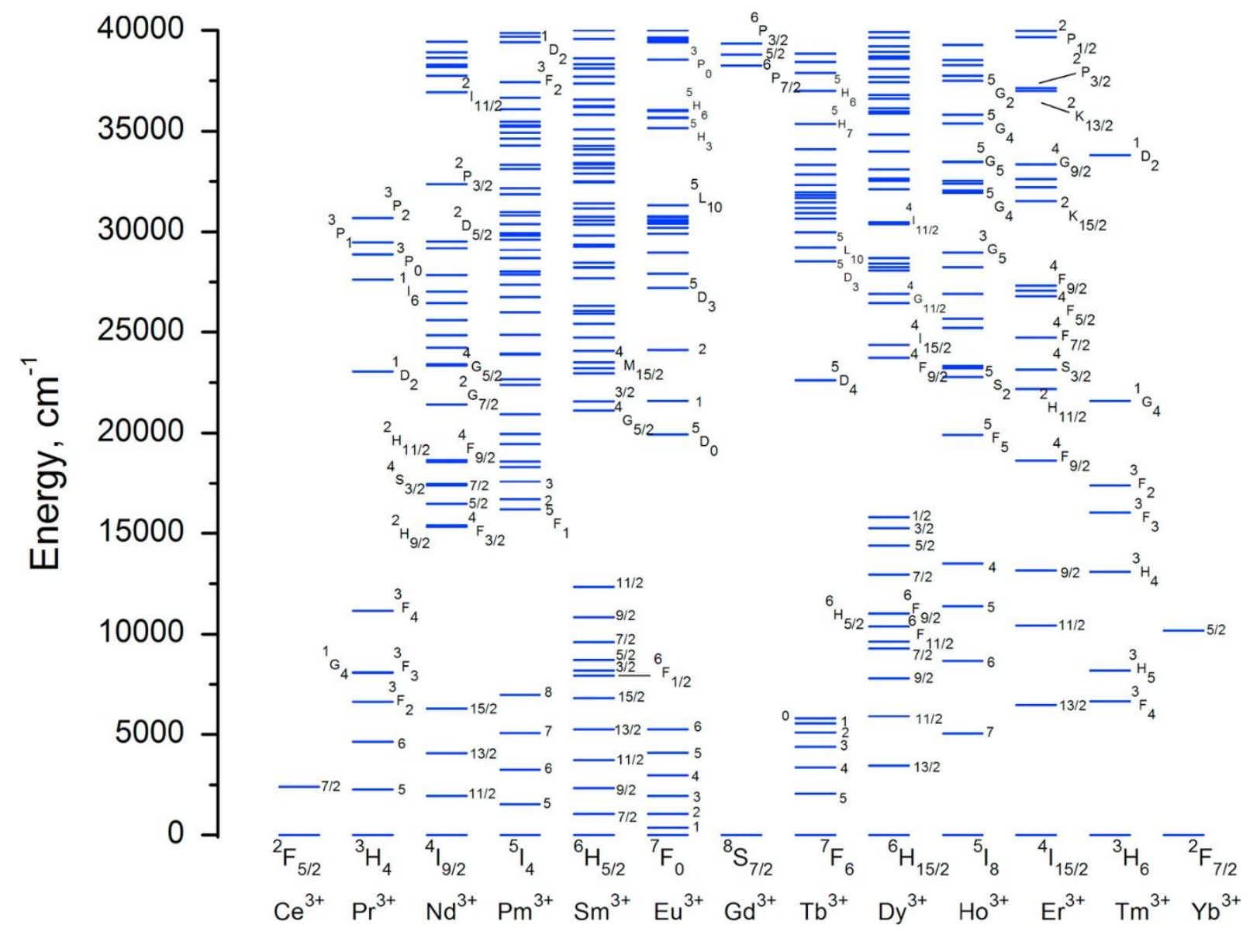

Fonte: (32).

Outra característica essencial para as aplicações dos íons lantanídeos é que suas transições eletrônicas ocorrem nos níveis associados à configuração $4 \mathrm{f}^{\mathrm{N}}$, e por isso são chamadas de transições $4 \mathrm{f}-4 \mathrm{f}$ ou intra-4f. Isto faz com que elas sejam permitidas por dipolo magnético $(17,29)$, que permite transições entre orbitais com mesma paridade, porém proibidas pela regra de seleção de Laporte, definida como: em uma espécie centro-simétrica, são permitidas por dipolo elétrico as transições entre orbitais com paridade oposta $(20,21,33)$. Em sistemas não centrossimétricos elas são observadas devido à uma mistura entre configurações com paridade oposta, relaxando essa regra de seleção $(21,29)$. Por serem proibidas essas transições são pouco intensas e, por conta de seu caráter atômico, apresentam picos finos. Outro fator importante que resulta dessas transições proibidas é que o tempo de vida do estado excitado torna-se bastante longo, na ordem de milissegundos $(20,21,23)$, enquanto moléculas orgânica possuem tempos de vida da ordem de nanosegundos $(33,34)$, devido a suas transições serem permitidas. 
Uma maneira de contornar a limitação da baixa absorção dos íons lantanídeos é o uso do chamado efeito antena, que consiste na absorção de energia por um cromóforo que transfere energia para o lantanídeo, aumentando assim a eficiência da absorção de luz (20). A Figura 6 apresenta o mecanismo de como o efeito antena pode aumentar a eficiência da emissão; em primeiro lugar, um fóton incide no sistema, sendo absorvido pelo cromóforo, promovendo-o para seu estado excitado, como este estado excitado é ressonante com o estado excitado do íon lantanídeo, há uma transferência de energia não radiativa entre eles, populando o estado excitado $L n^{*}$ do íon lantanídeo, que por sua vez retornará ao seu estado fundamental emitindo o fóton hv'. Como a transição $A^{*} \leftarrow A$ é uma transição permitida, o número de fótons absorvidos é muito maior do que os absorvidos pelo íon lantanídeo, aumentando assim a eficiência do sistema. Novamente, tomando o íon $\mathrm{Eu}^{3+}$ como exemplo, sua absortividade molar em solução aquosa é da ordem de $1 \mathrm{~mol} \cdot \mathrm{L}^{-1} \cdot \mathrm{cm}^{-1}(2)$, enquanto 0 complexo Eu(tta)sbipy possui uma absortividade molar de $19400 \mathrm{~mol} \cdot \mathrm{L}^{-1} \cdot \mathrm{cm}^{-1}$ quando solubilizado em clorofórmio, que consiste na absorção do complexo, em contrapartida da absortividade molar apenas do $\mathrm{Eu}^{3+}(35)$.

Figura 6 - Figura esquemática do mecanismo do efeito antena, onde hv indica o fóton incidente, hv' indica o fóton emitido, $A$ o estado fundamental do cromóforo que funciona como antena, $A^{*}$ seu estado excitado, Ln o estado fundamental do íon lantanídeo, $L n^{*}$ seu estado excitado, a seta preta representa a absorção do fóton incidente, a seta vermelha a emissão do fóton hv' e a seta verde a transferência de energia entre os estados excitados da antena e do lantanídeo.

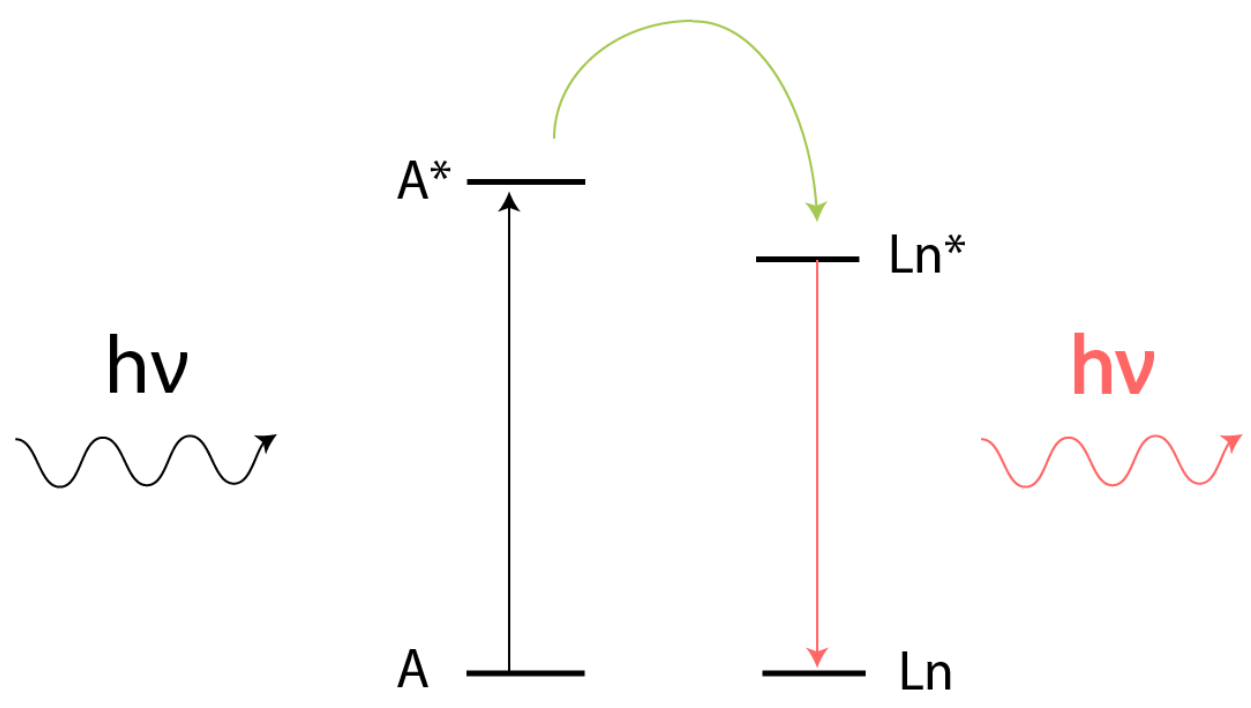

Fonte: adaptado de (20). 


\subsection{O íon $\mathrm{Eu}^{3+}$}

A luminescência do íon $\mathrm{Eu}^{3+}$ possui algumas peculiaridades que o tornam ideal para que ele seja utilizado como uma sonda espectroscopia para a simetria de sua primeira esfera de coordenação $(36,37)$, e tais propriedades serão discutidas nesta seção.

Como já discutido anteriormente, o campo cristalino pode quebrar a degenerescência dos níveis ${ }^{2 S+1}$ LJ dos lantanídeos em $2 J_{+} 1$ subníveis Stark $(2,29)$, e o número de componentes observadas no espectro de emissão será dependente do grupo de ponto em que o lantanídeo se encontra (20). A Tabela 3 mostra o número de componentes Stark observados em função do número J.

Tabela 3 - Número de componentes dos subníveis Stark observados em espectros de emissão do íon $E u^{3+}$ de acordo com o grupo de ponto em que ele se encontra

\begin{tabular}{lccccc}
\hline Grupo de ponto & $\mathrm{J}=0$ & $\mathrm{~J}=1$ & $\mathrm{~J}=2$ & $\mathrm{~J}=3$ & $\mathrm{~J}=4$ \\
\hline $\mathrm{Oh}_{\mathrm{h}}$ & 0 & 1 & 0 & 0 & 0 \\
$\mathrm{~T}_{\mathrm{d}}$ & 0 & 1 & 1 & 1 & 1 \\
$\mathrm{C}_{4 \mathrm{v}}$ & 1 & 2 & 2 & 2 & 4 \\
$\mathrm{~S}_{4}$ & 0 & 2 & 3 & 4 & 4 \\
$\mathrm{C}_{3}$ & 1 & 2 & 3 & 5 & 6 \\
$\mathrm{C}_{2 \mathrm{v}}$ & 1 & 3 & 5 & 7 & 9 \\
\hline
\end{tabular}

Fonte: (36).

A primeira característica importante a ser observada diz respeito à transição ${ }^{5} \mathrm{D}_{0} \rightarrow{ }^{7} \mathrm{~F}_{0}$. Esta transição é observada em baixas simetrias $\left(\mathrm{C}_{\mathrm{nv}}, \mathrm{C}_{\mathrm{n}}\right.$ ou $\left.\mathrm{C}_{\mathrm{s}}\right)$ não possui uma quebra de degenerescência sob influência de nenhum campo cristalino, com apenas um componente Stark, porém, a ocorrência de mais de um componente Stark indica que o $\mathrm{Eu}^{3+}$ está localizado em mais de um sítio com simetrias diferentes, desde que ela esteja presente nessas simetrias $(36,37)$, como por exemplo, a rede metalorgânica $\left.\mathrm{Eu}_{3}\left(\mathrm{C}_{14} \mathrm{H}_{6} \mathrm{~N}_{2} \mathrm{O}_{4}\right)_{4}(\mathrm{OH})\left(\mathrm{H}_{2} \mathrm{O}\right)_{4}\right] \cdot 2 \mathrm{H}_{2} \mathrm{O}$, no qual foram observadas duas componentes para a transição ${ }^{5} \mathrm{D}_{0} \rightarrow{ }^{7} \mathrm{~F}_{0}$ do $\mathrm{Eu}^{3+}$ que foram atribuídos à dois sítios com simetria distintas, e que foram mais tarde determinados por sua estrutura cristalina (38). 
Uma outra característica importante da emissão do íon $\mathrm{Eu}^{3+}$ é a razão entre a intensidade das transições ${ }^{5} \mathrm{D}_{0} \rightarrow{ }^{7} \mathrm{~F}_{2}$ e ${ }^{5} \mathrm{D}_{0} \rightarrow{ }^{7} \mathrm{~F}_{1}$. A transição entre os níveis ${ }^{5} \mathrm{D}_{0} \mathrm{e}$ ${ }^{7} \mathrm{~F}_{1}$ se dá por dipolo magnético, o que a torna sua intensidade fracamente dependente do ambiente químico, enquanto a transição entre os níveis ${ }^{5} \mathrm{D}_{0}$ e ${ }^{7} \mathrm{~F}_{2}$ é chamada transição hipersensível, cuja intensidade possui grande dependência da simetria local (36). A predominância da transição ${ }^{5} \mathrm{D}_{0} \rightarrow{ }^{7} \mathrm{~F}_{1}$ em detrimento da ${ }^{5} \mathrm{D}_{0} \rightarrow{ }^{7} \mathrm{~F}_{2}$ indica que o ambiente químico em que o $\mathrm{Eu}^{3+}$ se encontra possui uma alta simetria, como é o caso do $\mathrm{YF}_{3}: \mathrm{Eu}^{3+}$, cuja simetria é $\mathrm{D}_{4 \mathrm{~d}}$ e a emissão mais intensa é atribuída à emissão ${ }^{5} \mathrm{D}_{0} \rightarrow{ }^{7} \mathrm{~F}_{1}(36,39)$.

Um exemplo no qual o európio foi utilizado como sonda espectroscópica foi para determinação da quebra de simetria em estruturas cúbicas e hexagonais de $\mathrm{NaYF}_{4}$. Devido à uma pequena diferença entre os raios iônicos do $\mathrm{Y}^{3+} \mathrm{e}$ do $\mathrm{Eu}^{3+}$, quando há a dopagem com európio a simetria local muda de $\mathrm{O}_{\mathrm{h}}$ para $\mathrm{C}_{\mathrm{s}}$ na estrutura cúbica do $\mathrm{NaYF}_{4}$ e de $\mathrm{C}_{3 \mathrm{~h}}$ para $\mathrm{C}_{\mathrm{s}}$ na estrutura hexagonal do $\mathrm{NaYF}_{4}$ por conta do alongamento das ligações com o flúor (40).

A matriz estudada neste trabalho também teve o $\mathrm{Eu}^{3+}$ utilizado como sonda espectroscópica. O $\mathrm{LiYF}_{4}$ é um importante material para emissão laser do UV ao infravermelho médio (41), cuja estrutura cristalina é associada à scheelita (CaWO 4$)$, no qual o ítrio encontra-se em um sítio de simetria com número de coordenação igual à 8 e com simetria $S_{4}(42,43)$. Materiais com a mesma estrutura tetragonal do tipo scheelita, como o $\mathrm{SrWO}_{4}: \mathrm{Eu}^{3+}, \mathrm{Na}^{+}$confirmaram a simetria $\mathrm{S}_{4}$ pelos espectros de fotoluminescência (44). No espetro de luminescência do $\mathrm{Eu}^{3+}$ como dopante no $\mathrm{LiYF}_{4}$ não foi possível observar a transição ${ }^{5} D_{0} \rightarrow{ }^{7} F_{0}$, assim como a intensidade entre as transições ${ }^{5} \mathrm{D}_{0} \rightarrow{ }^{7} \mathrm{~F}_{1}$ e ${ }^{5} \mathrm{D}_{0} \rightarrow{ }^{7} \mathrm{~F}_{2}$ serem próximas, evidenciando um alto grau de simetria em seu ambiente químico $(14,43)$. Seu espectro de alta resolução permitiu confirmar que o desdobramento dos níveis Stark são compatíveis com a simetria $\mathrm{S}_{4}$ (14).

\subsection{Conversão ascendente de energia}

A conversão ascendente de energia é um mecanismo especial de fotoluminescência, onde temos emissão de energia do tipo anti-Stokes, ou seja, a emissão se dá em maiores energias do que a excitação devido à absorção sequencial 
de dois ou mais fótons (2). Esse fenômeno pode ocorrer em sistemas contendo lantanídeos por diferentes mecanismos, que foram descritos por Auzel $(45,46)$, no qual cada um deles possui uma eficiência diferente. Os dois mecanismos mais eficientes são chamados de conversão ascendente de energia por transferência de energia (do inglês, energy transfer upconversion, ETU) e absorção do estado excitado (do inglês, excited state absorption, ESA). Esses dois mecanismos e suas respectivas eficiências estão apresentados na Figura 7 a seguir. Outros mecanismos, não discutidos aqui, são a sensibilização cooperativa, luminescência cooperativa, geração de segundo harmônico e a excitação por absorção de dois fótons, com eficiências de $10^{-6}, 10^{-8}, 10^{-11}$ e $10^{-13}(46)$. Por terem eficiências muito baixas, a geração de segundo harmônico e absorção de dois fótons só podem ser observadas utilizando lasers pulsados e altas densidades de potência $\left(10^{6} \mathrm{~W} \cdot \mathrm{cm}^{-2}\right)$, enquanto os mecanismos ESA e ETU podem ser observados com excitações mais brandas, como lasers contínuos, lâmpadas de xenônio ou halogênios e até mesmo com luz solar focalizada (4).

Nota-se pelas eficiências descritas por Auzel, juntamente com a dependência com a distância para a transferência de energia descrita na seção 1.1, que sistemas que contenham íons ativadores próximos à sensibilizadores possuem maior eficiência. No caso de materiais com codopagem de $\mathrm{Yb} / \mathrm{Er}$, para maximizar a conversão ascendente de energia, são utilizadas altas concentrações de sensibilizador $\mathrm{Yb}^{3+}$ (na faixa de $20 \%$ de dopagem) para maximizar o ETU, assim como concentrações relativamente altas de $\mathrm{Er}^{3+}$ (próximas de $2 \%$ ) para que também possa ocorrer o ESA juntamente com o ETU, sem que haja supressão da emissão por concentração $(46,47)$. Comparando-se os rendimentos quânticos (razão entre número de fótons absorvidos e número de fótons emitidos) de compostos de $\mathrm{Tm}^{3+}$, verifica-se que o mecanismo de downshifting é muito mais eficiente, com rendimento quântico próximo à $63 \%$ para o composto $\mathrm{YVO}_{4}: \mathrm{Tm}$ (48), enquanto o rendimento quântico de upconversion para LiYF4:Yb,Tm é de 1,9\% para uma potência de excitação de 1 $W . \mathrm{cm}^{-2}$ (49). Vale notar que, apesar do baixo rendimento quântico, ainda é possível a observação da emissão de UC a olho nu. 
Figura 7 - Mecanismos de conversão ascendente de energia por transferência de energia e absorção do estado excitado.
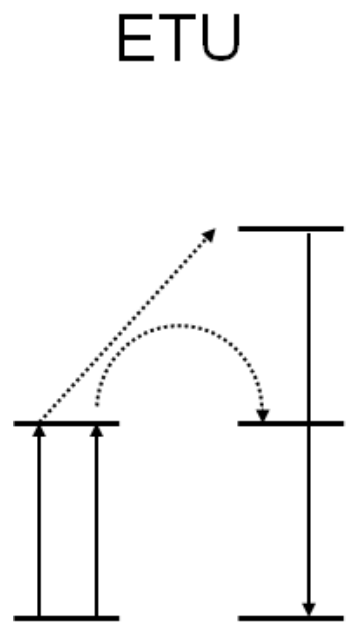

$\eta=10^{-3}$
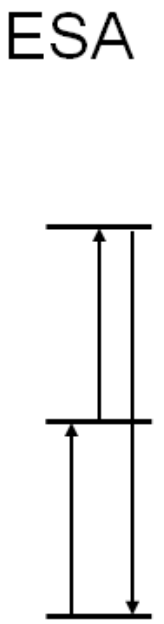

$\eta=10^{-5}$

Adaptado de (46).

O mecanismo ETU consiste na absorção de um fóton de energia por um sensibilizador que é promovido ao seu estado excitado, e transfere energia para o ativador; antes que o ativador possa retornar ao seu estado fundamental, o sensibilizador pode absorver mais um fóton e novamente transferir energia para o ativador, populando um estado excitado de maior energia; ao retornar ao estado fundamental do ativador, há a emissão de um fóton com energia igual à soma dos dois fótons absorvidos pelo sensibilizador $(4,46)$.

Já no mecanismo ESA, há a absorção de um fóton por uma espécie ativadora, que é promovida ao estado excitado e, antes de retornar ao estado fundamental, pode absorver outro fóton, populando um nível mais energético. O retorno ao estado fundamental resultará na emissão de um fóton com energia igual à soma dos dois fótons absorvidos $(4,46)$.

Nota-se pela descrição dos dois mecanismos que uma característica importante para ocorrer a conversão ascendente de energia é a necessidade de um longo tempo de vida do estado excitado intermediário para que a incidência de um segundo fóton ocorra, e isso torna os lantanídeos candidatos ideais para a conversão ascendente (15). 
Outro fator importante que deve ser apontado é a escolha da matriz em que os lantanídeos serão inseridos de forma a minimizar perdas não radiativas. Materiais com baixa energia de fônon são extensivamente utilizados como matriz para conversão ascendente de energia, uma vez que isso diminui a probabilidade de ocorrer relaxação multifônon (perda de energia não radiativa pela vibração coletiva da matriz), que diminuiria a população dos estados excitados dos lantanídeos $(47,50)$. A Tabela 4 mostra a energia de fônon de algumas matrizes utilizadas para esse propósito.

Tabela 4 - Energias de fônon para materiais comumente utilizados para conversão ascendente de energia

\begin{tabular}{cc}
\hline Material & Energia de fônon $\left(\mathrm{cm}^{-1}\right)$ \\
\hline Vidro fosfato & 1200 \\
Vidro silicato & 1100 \\
Vidro fluoreto & 550 \\
Vidro calcogeneto & 400 \\
$\mathrm{LaPO}_{4}$ & 1050 \\
$\mathrm{YAG}$ & 860 \\
$\mathrm{YVO}_{4}$ & 600 \\
$\mathrm{LaF}_{3}$ & 300 \\
$\mathrm{LaCl}_{3}$ & 240 \\
\hline
\end{tabular}

Fonte: (47).

Materiais à base de fluoretos são extensivamente explorados na literatura como matrizes para conversão ascendente de energia (50), sendo o melhor descrito na literatura o $\mathrm{NaYF}_{4}$, que pode ser sintetizado em duas estruturas cristalinas diferentes; a cúbica ( $\alpha$ ) e a hexagonal $(\beta)$, onde a $\beta$ possui uma intensidade de emissão (quando dopados) maior comparado com a $\alpha(51,52)$. A estrutura da fase cúbica é isomorfa ao $\mathrm{CaF}_{2}$, em que os íons $\mathrm{Y}^{3+}$ possuem uma simetria octaédrica (53), enquanto a fase hexagonal os íons $\mathrm{Y}^{3+}$ é $\mathrm{C}_{3 \mathrm{~h}}$ (54). Como a estrutura hexagonal não possui um centro de simetria, ao contrário da cúbica, as regras de seleção são mais relaxadas, explicando assim sua maior intensidade de emissão (55). 
Mais recentemente, uma outra matriz de fluoreto vem sendo explorada, o LiYF4. É reportado na literatura que a intensidade da emissão dos $\mathrm{LiYF}_{4}$ é 25 vezes mais intensa que do $\mathrm{NaYF}_{4}$, atribuída à uma menor distância entre os dopantes promovida pelo menor raio iônico do $\mathrm{Li}^{+}(56)$. Os métodos mais comuns de obtenção desse fluoreto são a hidrotermal (57-59) e decomposição térmica (60-63). É possível modular o tamanho dessas partículas a partir das condições experimentais tanto na decomposição térmica, quanto na síntese por meio hidrotermal. Na decomposição térmica, é reportado que modulando a quantidade de ácido oleico e oleilamina é possível obter nanopartículas de $\mathrm{LiYF}_{4}$ de 5 à $90 \mathrm{~nm}$ (64), enquanto em síntese hidrotermal, a variação na quantidade de $\mathrm{NaF}$ inicialmente colocada no tratamento hidrotermal foi capaz de alterar o tamanho das partículas de $53 \mathrm{~nm}$ até $77 \mathrm{~nm}$ (65).

Um dos grandes desafios para algumas possíveis aplicações, principalmente as biológicas, dessas partículas é que, na síntese por decomposição térmica, as partículas obtidas são hidrofóbicas $(16,52,61)$, e, para circunvir essa limitação, algumas estratégias são a retirada ou substituição de seus ligantes que o tornam hidrofóbico, como tratamento com ácido seguido de adição de ácido poliacrílico $(66,67)$, dendrímetros do tipo PAMAM $(68,69)$, modificação com sílica (70-73) ou ainda sua modificação com cisteína por epoxidação do ácido oleico e posterior abertura do anel epóxido (74). Neste trabalho a modificação com cisteína foi escolhida para posterior modificação com nanopartículas de ouro, como será explorado no capítulo 5.

Aplicações para essas partículas já foram exploradas, como plataformas de teranóstico (terapia e diagnóstico simultâneos) in vitro: uma estrutura do tipo núcleocasca-casca (core-shell-shell) de LiYF4:Yb,Tm-LiYF4-LiYF4:Nd foi sintetizada, na qual a emissão do $\mathrm{Nd}^{3+}$ pode ser utilizada para diagnóstico e a emissão do $\mathrm{Tm}^{3+}$ como terapia em células de câncer de mama (75). Os LiYF4 também foram utilizados para estimar a condutividade térmica de membranas celulares o que permitirá descrever com maior precisão os processos de transferência de calor em processos biológicos e de terapia, uma vez que os métodos convencionais de determinação de condutividade térmica se baseiam em contato elétrico e não seriam capazes de estimar com precisão em sistemas micrométricos (76).

A escolha dos íons lantanídeos na matriz também é essencial para que haja conversão ascendente de energia, já que, além do tempo de vida do estado excitado 
ser suficientemente alto para a incidência de um segundo fóton, é necessário que os estados excitados tenham energia compatível para a transferência de energia ou para a absorção de dois fótons. Alguns dos lantanídeos que apresentam conversão ascendente são $\circ \mathrm{Ho}^{3+}(62,77), \mathrm{Pr}^{3+}(78), \mathrm{Tm}^{3+}(79,80)$ e $\mathrm{Er}^{3+}$ (16,63). Um sensibilizador muito comum é o íon $\mathrm{Yb}^{3+}$; sua seção de choque é maior que dos ativadores mencionados anteriormente, o que aumenta a sua eficiência de absorção, além disso, sua transição ${ }^{2} \mathrm{~F}_{7 / 2} \rightarrow{ }^{2} \mathrm{~F}_{5 / 2}$ possui uma energia quase ressonante com transições dos ativadores mais comuns, como ${ }^{4} \mathrm{I}_{13 / 2}$ do $\mathrm{Er}^{3+}$ e $0{ }^{3} \mathrm{H}_{5}$ do $\mathrm{Tm}^{3+}$ (4). Ainda é possível fazer uma mistura entre os lantanídeos, alterando os que estão presentes no material ou ainda apenas mudar a proporção entre os dopantes para se alcançar diferentes perfis de cor emitida (81-84). Por exemplo, a emissão do NaYF4:Yb,Tm apresenta a coloração azul, porém, a presença e concentração de $E r^{3+}$ foi capaz de gradualmente alterar a coloração do azul para o branco (82).

Neste trabalho, foi escolhido o par de íons $\mathrm{Yb}^{3+} / \mathrm{Er}^{3+}$, por isso, seu mecanismo de conversão ascendente será explorado em maiores detalhes (Figura 8). 0 mecanismo predominante é o $\mathrm{ETU}$ do $\mathrm{Yb}^{3+}$ para o $\mathrm{Er}^{3+}$, porém vale destacar que o $\mathrm{ETU} \mathrm{Er}^{3+} \rightarrow \mathrm{Er}^{3+}$ e o ESA do $\mathrm{Er}^{3+}$ também são mecanismos possíveis. Em primeiro lugar, uma excitação em $980 \mathrm{~nm}$ utilizando um laser contínuo incide sobre o material, fazendo com que $\circ \mathrm{Yb}^{3+}$ passe do estado fundamental ${ }^{2} \mathrm{~F}_{7 / 2}$ para o estado excitado ${ }^{2} \mathrm{~F}_{5 / 2} \mathrm{e}$, em seguida, transfere energia para o $\mathrm{Er}^{3+}$, populando o nível $\left.{ }^{4}\right|_{11 / 2}$. Após um segundo fóton ser absorvido pelo $\mathrm{Yb}^{3+}$, há uma segunda transferência de energia para o $\mathrm{Er}^{3+}$, que pode popular o estado ${ }^{4} \mathrm{~F}_{7 / 2}$, no qual ocorrerão decaimentos não radiativos até os estados emissores ${ }^{2} \mathrm{H}_{11 / 2},{ }^{4} \mathrm{~S}_{3 / 2}$ e ${ }^{4} \mathrm{~F}_{9 / 2}$, gerando emissões na região do verde $\mathrm{e}$ do vermelho $(4,16,59,85)$. 
Figura 8 - Diagrama de níveis de energia dos íons $\mathrm{Yb}^{3+}$ e $\mathrm{Er}^{3+}$ e mecanismos de conversão ascendente de materiais dopados com esses lantanídeos.

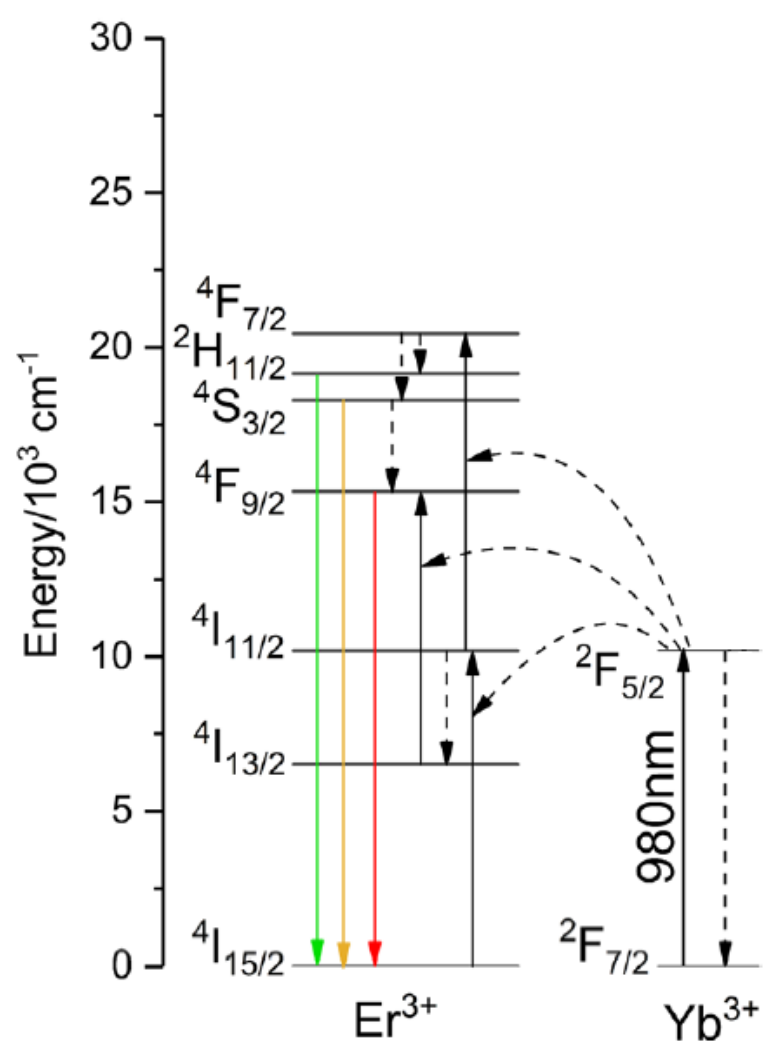

Fonte: adaptado de (86).

Emissões com um número de fótons maior do que 2 também podem ser observadas, como no caso do $\mathrm{LiYF}_{4}: \mathrm{Yb}^{3+}, \mathrm{Tm}^{3+}$, no qual foram observados processos envolvendo 3 fótons e uma emissão no UV que pode ser atribuída à um processo de 5 fótons (61). O par de íons $\mathrm{Yb} / \mathrm{Er}$ também pode apresentar processos de 3 fótons, como observado para o $\mathrm{Y}_{2} \mathrm{SiO}_{5}: \mathrm{Yb}, \mathrm{Er}$, com a emissão ${ }^{2} \mathrm{H}_{9 / 2} \rightarrow{ }^{4} \mathrm{I}_{15 / 2}$ observada em 405 nm (87). Para calcular o número de fótons envolvidos em um processo de conversão ascendente de energia, se utiliza o fato de a intensidade variar em função da potência de acordo com a equação $6(88,89)$ :

$$
I \propto P^{n}
$$

onde I é a intensidade de emissão, $\mathrm{P}$ a potência do laser de excitação utilizado e $\mathrm{n}$ o número de fótons envolvidos no processo. Portanto, ao se fazer o gráfico do logarítmico da intensidade em função do logaritmo da potência utilizada para a excitação, o número de fótons envolvidos no processo de conversão ascendente será dado pelo coeficiente linear da reta obtida $(46,61,89,90)$. 


\subsection{Temperatura e termômetros luminescentes}

A temperatura é uma propriedade termodinâmica fundamental, e uma variável de extrema importância para a descrição de qualquer sistema, seja ele natural ou não $(91,92)$. O funcionamento de termômetros depende de manifestações físicas ou efeitos moleculares reprodutíveis, que se relacionam com a mudança de temperatura (91).

Os termômetros podem ser classificados dependendo da natureza do contato entre o sensor e o objeto da análise (93), sendo eles:

- Termômetros invasivos (ou termômetros de contato): O sensor encontra-se em contato direto com o meio a ser analisado. Exemplo: termopares

- Termômetros semi-invasivos: O sensor modifica o meio de interesse para análise remota de sua temperatura. Exemplo: tintas térmicas

- Termômetros não invasivos: a temperatura do meio a ser analisado é observada remotamente. Exemplo: termometria de radiação de corpo negro.

Há, ainda, uma segunda maneira de classificá-los, sendo em primários ou secundários. Termômetros secundários são aqueles que necessitam de uma calibração feita comparando com uma referência, enquanto os primários seguem uma equação de estado para medir a temperatura absoluta diretamente de uma medida (94-96).

É sabido que algumas características luminescentes podem mudar em função da temperatura, como intensidade e tempo de vida, por exemplo (97). A utilização da luminescência como sensor de temperatura inicia-se com Paul Neubert, em 1932, no qual um material composto de ZnS e Cu tinha sua emissão suprimida em função da temperatura (97). Com o advento de novas tecnologias, avanço das existentes e miniaturização dos sistemas, os termômetros convencionais, como os à base da expansão do mercúrio e termopares não foram capazes de atender às demandas, uma vez que suas resoluções espaciais são da ordem de $10 \mu \mathrm{m}(91,93)$. Por esse motivo, a luminescência de moléculas e nanopartículas vem atraído atenção por não apresentar essa limitação, uma vez que suas dimensões são inferiores à limitação imposta pelos termopares e termômetros convencionais. 
Diversos tipos de nanomateriais luminescentes já foram explorados para diferentes tipos de aplicação. A GFP extraída de Aequorea victoria foi utilizada para medir diferenças de temperatura em mitocôndrias de células in vitro (98), quantum dots comerciais foram para detecção de gradientes de temperatura em células neurais, também in vitro (99), ambos baseados na razão de intensidade entre dois comprimentos de onda diferentes. Polímeros também foram explorados para bioimageamento e medidas de temperatura simultâneos; tais polímeros são compostos de três unidades: uma que responderá à mudança de temperatura, em que à baixas temperaturas ela se encontra em um estado estendido, e com o aumento da temperatura tende a se enovelar, a segunda unidade garante hidrofilicidade ao polímero e a terceira unidade é a sonda fluorescente, que tem seu tempo de vida do estado excitado modificado em função da interação com a primeira unidade (100).

Além desses já citados, materiais baseados em lantanídeos para imageamento térmico de microcircuitos eletrônicos, em que uma nanopartícula dopada com $\mathrm{Yb}^{3+} / \mathrm{Er}^{3+}$ foi colocada em uma ponteira de microscopia de força atômica e foi possível acompanhar mudanças de temperatura de um circuito (101). Além disso, com nanopartículas de $\mathrm{NaYF}_{4}: \mathrm{Yb}^{3+}, \mathrm{Er}^{3+}$ foi possível acompanhar o aquecimento de células de câncer cervical in vitro (102) e até mesmo para estimar a condutividade térmica de membranas celulares a partir de nanopartículas de $\mathrm{LiYF}_{4}$ modificadas com uma bicamada lipídica, como já citado na seção 1.4. Tanto as nanopartículas quanto a água são capazes de converter a excitação do laser em $980 \mathrm{~nm}$ em calor, aquecendo o sistema. A equação 7 foi utilizada para se estimar a condutividade térmica da camada lipídica (76).

$$
\Delta T_{\max }=\left[\frac{1}{\kappa_{f}}\left(\frac{\alpha L^{2} A_{b}}{A_{s}}+\frac{N \sigma_{L}}{4 \pi \beta_{L} r_{L}}\right)\right]+\frac{N \sigma_{P}}{4 \pi \beta_{P} r_{P}} P_{d}
$$

onde o primeiro termo na somatória entre parênteses leva em conta o aquecimento pela água, o segundo termo pelo aquecimento devido à bicamada lipídica e o termo fora dos colchetes o aquecimento gerado pelas nanopartículas. O $\Delta T_{\max }$ é o aquecimento máximo gerado no sistema e $P_{d}$ é a densidade de potência do laser.

Portanto, estimando-se as contribuições separadamente da água e das nanopartículas não modificadas, foi possível calcular a condutividade térmica da bicamada lipídica, que foi considerada um modelo mimético para membranas 
celulares (76). Mais detalhes serão abordados no Capítulo 5, uma vez que o mesmo procedimento foi utilizado para estimar a condutividade térmica de solventes.

Em relação aos materiais orgânicos apresentados, os materiais baseados em lantanídeos possuem algumas características que podem ser consideradas vantajosas, a depender de sua aplicação. Os elevados tempos de vida dos estados excitados, por exemplo, fazem com que seja fácil evitar a fluorescência de outros compostos orgânicos presentes em ambiente celular (103). Além disso, a utilização da conversão ascendente de energia com lantanídeos oferece uma grande vantagem, já que a excitação se dá na região de 980 nm, onde há maior penetração da radiação em tecidos (104).

Dois principais tipos de termômetros baseados em $\mathrm{Eu}^{3+}$ são descritos utilizando-se a emissão do tipo downshifting, sendo eles os baseados na intensidade de emissão e os baseados em espectroscopia resolvida no tempo. Lojpur e colaboradores descreveram o rise time (tempo em que o nível emissor ainda está sendo populado por relaxação não radiativa dos estados excitados mais energéticos) do $\mathrm{Eu}^{3+}$ quando dopante na matriz $\mathrm{SrY}_{2} \mathrm{O}_{4}$ como uma função linear na faixa de temperatura de $293 \mathrm{~K}$ até $473 \mathrm{~K}(96)$, e Li e colaboradores descreveram o rise time do material $\mathrm{BaY}_{2} \mathrm{ZnO}_{5}: \mathrm{Eu}^{3+}$ com uma boa correlação com a temperatura de $330 \mathrm{~K}$ à 510 $\mathrm{K}$ (105), enquanto o complexo $\mathrm{Eu}(\mathrm{bzac})_{3}\left(\mathrm{H}_{2} \mathrm{O}\right)_{2}$ teve seu tempo de vida em função da temperatura explorado na faixa de $75 \mathrm{~K}$ à $300 \mathrm{~K}$ (13). A dependência do tempo de vida radiativo com a temperatura é atribuído à relaxação não radiativa da matriz, diminuindo o tempo de vida radiativo à altas temperaturas (106).

Utilizando a intensidade das transições, o mesmo complexo citado anteriormente $\left(\mathrm{Eu}(\mathrm{bzac})_{3}\left(\mathrm{H}_{2} \mathrm{O}\right)_{2}\right)$ pode ser descrito como termômetro com a transição ${ }^{5} \mathrm{D}_{0} \rightarrow{ }^{7} \mathrm{~F}_{0}$, que tem sua intensidade suprimida à altas temperaturas, também por relaxação via fônon (13), e $\mathrm{Y}_{2} \mathrm{O}_{3}: \mathrm{Eu}^{3+}$ utilizou-se da razão da transição ${ }^{5} \mathrm{D}_{0} \rightarrow{ }^{7} \mathrm{~F}_{4}$ em duas excitações diferentes: as transições ${ }^{5} \mathrm{D}_{0} \rightarrow{ }^{7} \mathrm{~F}_{2}$ e ${ }^{5} \mathrm{D}_{0} \rightarrow{ }^{7} \mathrm{~F}_{0}$ (107). O LiYF $4: \mathrm{Eu}^{3+}$ possui transições oriundas do estado excitado ${ }^{5} D_{1}$, o que permitiu que Meert e colaboradores utilizassem a razão entre as transições ${ }^{5} D_{1} \rightarrow{ }^{7} F_{1}$ e ${ }^{5} D_{0} \rightarrow{ }^{7} F_{1}$ para a caracterização de um termômetro luminescente de $\mathrm{Eu}^{3+}$, uma vez que estes estados excitados são termicamente acoplados (108). A razão para a escolha dessas transições específicas se deve à falta de sobreposição de outras transições nas regiões em que elas ocorrem, facilitando a interpretação do resultado. 
A conversão ascendente de energia também do íon $\mathrm{Er}^{3+}$ também pode ser utilizada como sensor de temperatura, utilizando-se uma equação de distribuição de Boltzmann (93), cuja dedução se encontrará em detalhes mais à frente. Um vidro telurito dopado com $\mathrm{Yb}^{3+}$ e $\mathrm{Er}^{3+}$ apresentou linearidade de $278 \mathrm{~K}$ à $473 \mathrm{~K}$ (109), assim como nanopartículas de $\mathrm{SrF}_{2}: \mathrm{Yb}^{3+}, \mathrm{Er}^{3+}$ apresentaram linearidade da intensidade de emissão entre $300 \mathrm{~K}$ e $380 \mathrm{~K}$ (95) e nanopartículas de $\mathrm{NaYF}_{4}: \mathrm{Yb}^{3+}, \mathrm{Er}^{3+}$ foram capazes de medir variações de temperatura em células de câncer cervical entre $298 \mathrm{~K}$ e $318 \mathrm{~K}(102)$.

Tanto o $\mathrm{Eu}^{3+}$ quanto o $\mathrm{Er}^{3+}$ possuem níveis termicamente acoplados, como mostrado na Figura 9. O Eu ${ }^{3+}$ possui os níveis ${ }^{5} D_{1}$ e ${ }^{5} D_{0}$ com diferença de energia próxima aos $1800 \mathrm{~cm}^{-1}$, enquanto $\circ \mathrm{Er}^{3+}$ possui uma diferença de energia entre $\mathrm{O}$ ${ }^{2} \mathrm{H}_{11 / 2}$ e $0{ }^{4} \mathrm{~S}_{3 / 2}$ de aproximadamente $800 \mathrm{~cm}^{-1}(21)$, tornando ambos aptos para se a termometria luminescente.

Figura 9- Diagrama de níveis de energia do Eu ${ }^{3+}$, evidenciando a diferença de energia entre os estados excitados ${ }^{5} D_{0} e^{5} D_{1}$, e do $E r^{3+}$, evidenciando a diferença de energia dos níveis ${ }^{2} H_{11 / 2} e^{4} S_{3 / 2}$.
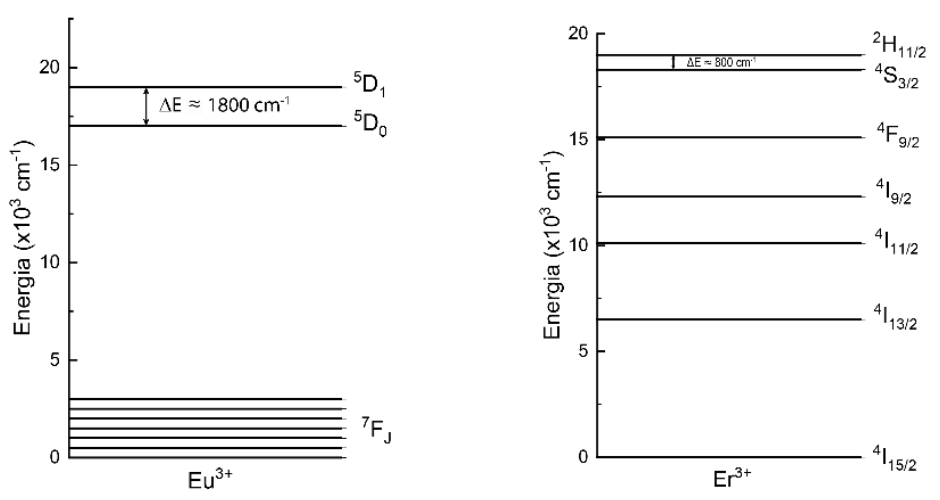

Fonte: o autor.

Os termômetros luminescentes que serão descritos neste trabalho terão como base a razão entre a intensidade de dois níveis emissores que são termicamente acoplados, isso significa que a diferença de energia entre eles está entre $200 \mathrm{~cm}^{-1} \mathrm{e}$ $2000 \mathrm{~cm}^{-1}$, permitindo que a temperatura despopule um deles em detrimento do outro (93). Tomando como exemplo um material com o diagrama de níveis de energia representado na Figura 10, a população desses dois níveis excitados representados seguirá uma distribuição de Boltzmann (Equação 8): 
Figura 10 - Diagrama de níveis de energia hipotético para um material que servirá de termômetro.

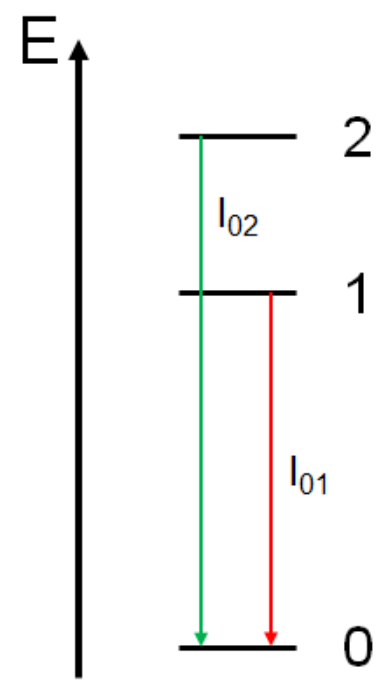

Adaptado de (90).

$$
N_{2}=N_{1}\left(\frac{g_{2}}{g_{1}}\right) \exp \left(\frac{-\Delta E}{k_{b} T}\right)
$$

onde $g_{\mathrm{n}}$ é a degenerescência do nível $n, \Delta \mathrm{E}$ a diferença de energia entre o baricentro das transições, kb a constante de Boltzmann e $\mathrm{T}$ a temperatura. Como a intensidade de emissão é proporcional à população dos níveis e ao decaimento espontâneo, podemos escrever que a relação da intensidade entre duas emissões é descrita pela Equação 9:

$$
\Delta=\frac{I_{02}}{I_{01}}=B \exp \left(\frac{-\Delta E}{k_{b} T}\right)
$$

na qual B é uma constante dependente da degenerescência do estado excitado, das taxas de emissão espontâneas dos estados excitados e das frequências angulares das transições, que podem ser calculados utilizando os parâmetros de Judd-Ofelt (93).

Como visto anteriormente na Figura 9, a diferença entre os estados excitados ${ }^{5} D_{0}$ e ${ }^{5} D_{1}$ do $E u^{3+}$ possuem uma diferença de energia da ordem de $1800 \mathrm{~cm}^{-1}$, o que os torna termicamente acoplados (108). Com isso, pode-se obter um termômetro com base na relação de intensidade do $\mathrm{Eu}^{3+}$ que segue a equação 10 (108): 


$$
\Delta=\frac{I_{5_{D_{1}} \rightarrow{ }^{7} F_{1}}}{I_{{ }_{D_{0}} \rightarrow{ }^{7} F_{1}}}=B \exp \left(\frac{-\Delta E}{k_{b} T}\right)
$$

Para os termômetros baseados na emissão do íon $\mathrm{Er}^{3+}$ por conversão ascendente de energia, ainda é possível eliminar a dependência com o valor de B, utilizando a equação $11(76,93,95)$ :

$$
\frac{1}{T}=\frac{1}{T_{0}}-\frac{k_{b}}{\Delta E} \ln \left(\frac{\Delta}{\Delta_{0}}\right)
$$

onde $T_{0}$ é a temperatura onde não há aquecimento induzido pelo laser de excitação e $\Delta_{0}$ o parâmetro de intensidade nessa temperatura, que pode ser calculado pela extrapolação do gráfico de $\Delta$ em função da potência do laser para o laser desligado $(\mathrm{P}=0)$.

A partir disso, foi possível caracterizar as propriedades das nanopartículas de $\mathrm{LiYF}_{4}$ como termômetros luminescentes. Em seguida, essas partículas puderam ser modificadas com nanopartículas de ouro, na expectativa de gerar aquecimento do sistema.

\subsection{Nanopartículas de ouro}

Dentro do contexto deste trabalho, foi proposta uma transferência de energia entre o lantanídeo e nanopartículas de ouro, com um possível aquecimento localizado do sistema para futuras aplicações em terapia fototérmica.

Esferas de ouro metálico com tamanho nanométrico (de 1 à $100 \mathrm{~nm}$ ) possuem uma forte absorção na região de $520 \mathrm{~nm}(110,111)$, dando origem à uma cor avermelhada (111). Tal absorção de luz tem origem de um fenômeno chamado ressonância de plasmon de superfície (SPR, do inglês, Surface Plasmon Resonance) (112).

O fenômeno de SPR ocorre devido à interação entre as ondas eletromagnéticas (luz) e os elétrons superficiais das nanopartículas, causando uma oscilação coerente destes elétrons $(110,111)$. Esta oscilação da nuvem eletrônica do metal cria duas regiões com cargas opostas (Figura 11), fazendo com que seja gerada uma força para restaurar a nuvem eletrônica para a posição de equilíbrio (112). Tal interação se dá 
quando o tamanho da nanopartícula é da ordem do comprimento de onda da luz incidente (112). O comprimento de onda em que se dá a absorção das nanopartículas de ouro está diretamente ligado com seu tamanho $(113,114)$. Com isso, é possível modular a região espectral na qual ocorrerá a absorção.

Figura 11 - Geração de uma oscilação na nuvem eletrônica de uma nanopartícula de ouro por meio da incidência de radiação eletromagnética.

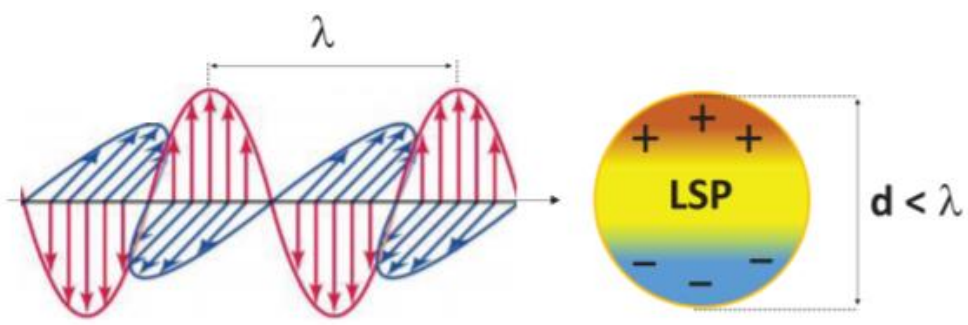

Fonte: (109).

Existem diferentes métodos de síntese para as nanopartículas de ouro; o método Brust-Schiffrin utiliza-se de um catalisador de transferência de fase para transferir um precursor de ouro $\left(\mathrm{HAuCl}_{4}\right)$ de uma fase aquosa para uma fase orgânica, que em seguida é reduzido por um agente redutor $\left(\mathrm{NaBH}_{4}\right)$, formando as nanopartículas de ouro (115). Também é utilizado o mesmo agente redutor em soluções aquosas de $\mathrm{HAuCl}_{4}$ para preparação de sementes (pequenos núcleos) e posterior crescimento desses núcleos, obtendo um controle de tamanho de partículas entre 5 e $40 \mathrm{~nm}$ (113). Aminoácidos também foram investigados como agentes redutores, com bons resultados obtidos com asparagina e histidina, por exemplo, produzindo partículas de aproximadamente $4 \mathrm{~nm}$ (116).

Um método de síntese bastante utilizado para a síntese de nanopartículas de ouro foi descrito por Turkevich em 1951 (117), que consiste na redução de $\mathrm{HAuCl}_{4}$ por citrato de sódio à $100^{\circ} \mathrm{C}$, produzindo nanopartículas esféricas de $20 \mathrm{~nm}$. Controlando a concentração de precursor, agente redutor, concentração de $\mathrm{Cl}^{-}$e $\mathrm{pH}$, ainda é possível obter partículas de até $5 \mathrm{~nm}$ (118) e, ainda, utilizando síntese por crescimento de sementes, é possível controlar o tamanho entre 15 e 300 nm (114).

Além da temperatura, também é possível utilizar um tratamento com plasma de hélio para catalisar a redução de $\mathrm{HAuCl}_{4}$ para $\mathrm{Au}^{0}$. Aplicando-se uma alta voltagem em uma seringa com fluxo de gás hélio, é possível gerar um jato de plasma que, direcionado à uma solução aquosa contendo $\mathrm{HAuCl}_{4}$ e citrato de sódio, foram formadas nanopartículas de ouro (9) (Figura 12). Neste caso, o citrato de sódio não 
age como redutor, sendo apenas um estabilizador eletrostático para as nanopartículas; a redução do $\mathrm{Au}^{3+}$ pode feita pela produção de $\mathrm{H}_{2} \mathrm{O}_{2}$ gerado pelo plasma na interface com a água $(9,119,120)$, de acordo com as reações a seguir:

$$
\left\{\begin{aligned}
e_{g a s}^{-}+\mathrm{H}_{2} \mathrm{O} & \rightarrow \mathrm{OH}^{\bullet}+\mathrm{H}^{-} \\
2 \mathrm{OH}^{\bullet} & \rightarrow \mathrm{H}_{2} \mathrm{O}_{2} \\
3 \mathrm{H}_{2} \mathrm{O}_{2}+6 \mathrm{OOH}^{-}+2 \mathrm{Au}^{3+} & \rightarrow 2 \mathrm{Au}^{0}+3 \mathrm{O}_{2}+6 \mathrm{H}_{2} \mathrm{O}
\end{aligned}\right.
$$

Figura 12 - Desenho esquemático do experimento de geração de plasma de He a partir de um gerador de baixa frequência (LFG), um amplificador de potência e um transformador gerando uma descarga no eletrodo. Esta descarga será responsável pela geração do plasma de He na seringa.

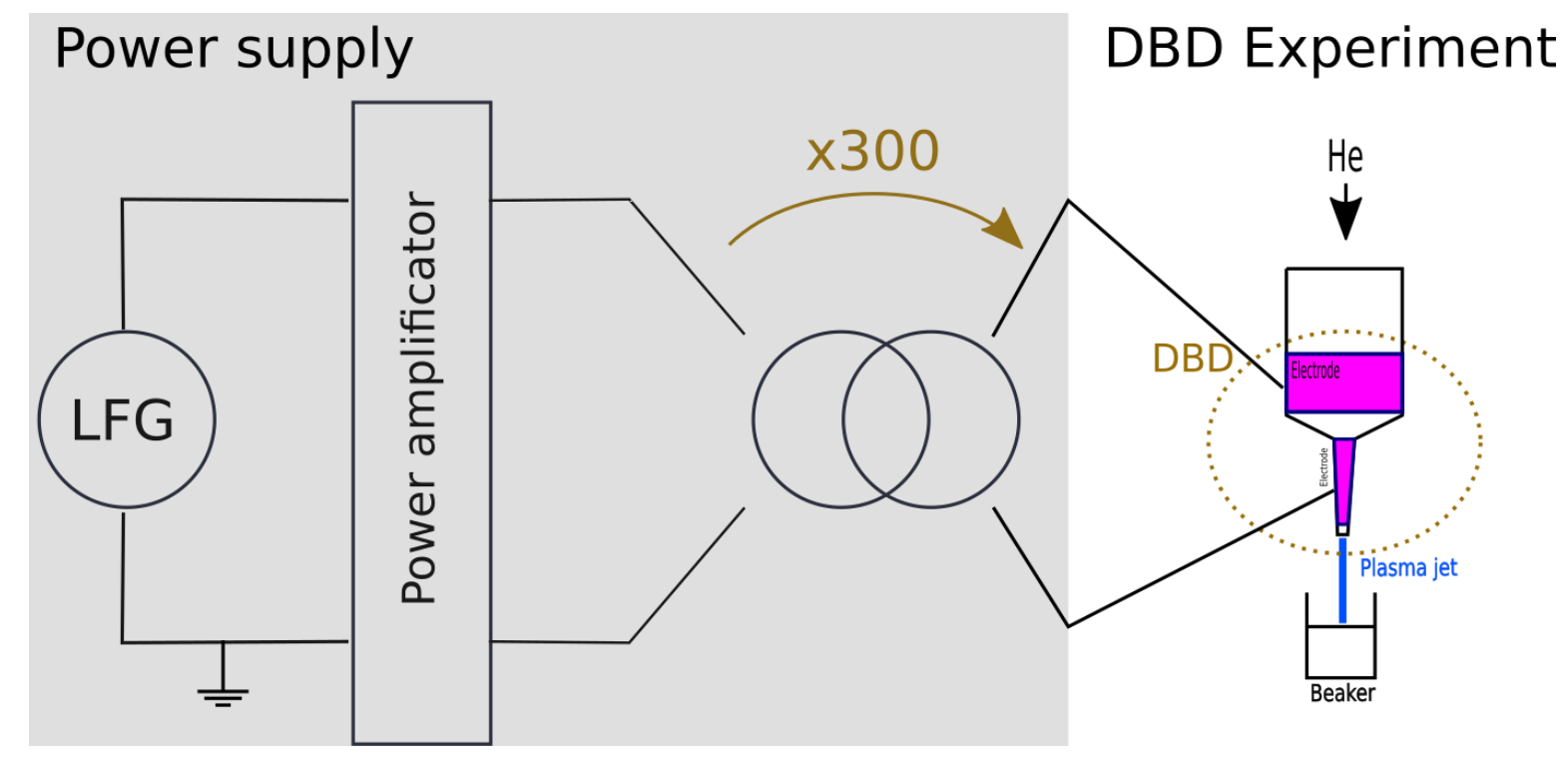

Fonte: (9)

Além da absorção de luz visível pela SPR, as nanopartículas de ouro (AuNPs, do inglês, Au NanoParticles) podem gerar um aumento de temperatura local por conta da oscilação de sua nuvem eletrônica $(110,121)$. A energia absorvida pela AuNP pela excitação na região da banda de SPR pode ser convertida em calor por processos não radiativos, aumentando a temperatura de seu ambiente local por relaxação multifônon (110).

Este aumento de temperatura local foi utilizado para liberação controlada em lipossomos, por exemplo. Wu e colaboradores foram capazes de controlar a liberação de 6-carboxifluoresceína em um lipossomo a partir da excitação de nanocascas ocas de ouro, que aqueceram seu ambiente promovendo a formação de bolhas de vapor que foram capazes de destruir a integridade do lipossomo (122). 
Além de liberação controlada, esse efeito térmico de AuNPs pode ser utilizada para terapia fototérmica, em que o aquecimento é utilizado para o tratamento. O'Neal e colaboradores detectaram uma temperatura de $50^{\circ} \mathrm{C}$ em células de câncer de cólon de camundongos utilizando terapia fototérmica com AuNPs, que foram capazes de eliminar os tumores em 10 dias (123). Rengan e colaboradores utilizaram AuNPs em lipossomos para a remoção de fibrossarcomas em camundongos por terapia fototérmica (124).

A partir disso, foi proposta a modificação das nanopartículas de $\mathrm{LiYF}_{4}$ com nanopartículas de ouro, de modo a obter uma ressonância entre a emissão dos lantanídeos com a absorção do ouro, na expectativa de que haja uma geração de aquecimento localizado que possa ser utilizado futuramente como terapia fototérmica. 


\subsection{Objetivos}

O objetivo central deste trabalho foi a obtenção de nanopartículas luminescentes à base de íons lantanídeos para atuarem como termômetros primários.

Para isso, alguns objetivos intermediários foram propostos:

- Síntese de nanopartículas de $\mathrm{LiYF}_{4}$ pelo método de decomposição térmicas não dopadas, dopadas com $\mathrm{Eu}^{3+}$, ou codopadas com o par $\mathrm{Yb}^{3+} / \mathrm{Er}^{3+}$;

- Caracterização estrutural e espectroscópica das nanopartículas obtidas;

- Visando futuras aplicações biológicas, mudança no perfil hidrofóbico das partículas obtidas por decomposição térmica para hidrofílico;

- Estudo da dependência dos perfis espectrais em função da temperatura, via downshifting ou conversão ascendente de energia;

- Modificação das nanopartículas de $\mathrm{LiYF}_{4}$ com nanopartículas de ouro,

- Estudo do possível efeito fototérmico causado pela presença de nanopartículas de ouro. 


\subsection{REFERÊNCIAS}

1 Verhoeven, J.W. Glossary of terms used in photochemistry (IUPAC Recommendations 1996). v. 68, n. 12, p. 2223, 1996.

2 Blasse, G.; Grabmaier, B.C. Luminescent Materials. Heidelberg: Springer, 1997.

3 Lian, H.; Hou, Z.; et al. Rare earth ions doped phosphors for improving efficiencies of solar cells. Energy, v. 57, p. 270-283, 2013.

4 Zhou, J.; Liu, Q.; et al. Upconversion luminescent materials: advances and applications. Chem Rev, v. 115, n. 1, p. 395-465, 2015.

5 Barni, F.; Lewis, S.W.; et al. Forensic application of the luminol reaction as a presumptive test for latent blood detection. Talanta, v. 72, n. 3, p. 896-913, 2007.

6 Moszyński, M.; Balcerzyk, M.; et al. Characterization of CaWO4 scintillator at room and liquid nitrogen temperatures. Nuclear Instruments and Methods in Physics Research Section A: Accelerators, Spectrometers, Detectors and Associated Equipment, v. 553, n. 3, p. 578-591, 2005.

7 Suslick, K.S.; Flint, E.B.; et al. Sonoluminescence from metal carbonyls. The Journal of Physical Chemistry, v. 97, n. 13, p. 3098-3099, 1993.

8 Zink, J.I.; Hardy, G.E.; et al. Triboluminescence of sugars. The Journal of Physical Chemistry, v. 80, n. 3, p. 248-249, 1976.

9 Gonçalves, J.M.; Guillot, P.; et al. Atmospheric plasma-assisted modification of nanosized LiYF4:Eu3+ with gold nanoparticles. Journal of Materials Science: Materials in Electronics, v. 30, n. 18, p. 16724-16731, 2019.

10 Le, K.Q.; Dang, N.H. Photoluminescence Spectroscopy of Rhodamine 800 Aqueous Solution and Dye-Doped Polymer Thin-Film: Concentration and Solvent Effects. Journal of Electronic Materials, v. 47, n. 8, p. 4813-4817, 2018.

11 Heim, R.; Prasher, D.C.; et al. Wavelength mutations and posttranslational autoxidation of green fluorescent protein. Proceedings of the National Academy of Sciences, v. 91, n. 26, p. 12501, 1994.

12 Costa-Fernández, J.M.; Pereiro, R.; et al. The use of luminescent quantum dots for optical sensing. TrAC Trends in Analytical Chemistry, v. 25, n. 3, p. 207-218, 
2006.

13 Gálico, D.A.; Mazali, I.O.; et al. Nanothermometer based on intensity variation and emission lifetime of europium(III) benzoylacetonate complex. Journal of Luminescence, v. 192, p. 224-230, 2017.

14 Görller-Walrand, C.; Behets, M.; et al. Analysis of the fluorescence spectrum of LiYF4:Eu3+. Inorganica Chimica Acta, v. 109, n. 2, p. 83-90, 1985.

15 Ronda, C. Luminescente: from theory to applications. Weinheim: Wiley-VCH, 2007.

16 Boyer, J.C.; Vetrone, F.; et al. Synthesis of colloidal upconverting NaYF4 nanocrystals doped with Er3+, Yb3+ and Tm3+, Yb3+ via thermal decomposition of lanthanide trifluoroacetate precursors. J Am Chem Soc, v. 128, n. 23, p. 7444-7445, 2006.

17 Yen, W.M.; Shionoya, S.; et al. Phosphor Handbook. $2^{\text {nd }}$ edition. Boca Raton: CRC Press, 2006.

18 Jones, G.A.; Bradshaw, D.S. Resonance Energy Transfer: From Fundamental Theory to Recent Applications. Frontiers in Physics, v. 7, p. 100, 2019.

19 Dexter, D.L. A Theory of Sensitized Luminescence in Solids. The Journal of Chemical Physics, v. 21, n. 5, p. 836-850, 1953.

20 Cotton, S. Lathanide and actinide chemistry. West Sussex: John Wiley \& Sons, Ltd, 2006.

21 Sastri, V.R.; Perumareddi, J.R.; et al. Modern aspects of rare earths and their complexes. Amsterdam: Elsevier, 2003.

22 Abrão, A. Química e tecnologia das terras-raras. Rio de Janeiro: CETEM/CNPq, 1994.

23 Atkins, P., et al. The f-block elements. In : Shriver \& Atkins Inorganic Chemistry. $5^{\text {th }}$ edition. New York: W. H. Freeman and Company, 2010, cap. 23, p. 579-598. 
24 McQuarrie, D.A., Simon, J.D. The Schödinger Equation and a Particle in a Box. In : Physical Chemistry A Molecular Apporach. Sausalito: University Science Books, 1997,

25 Freeman, A.J.; Watson, R.E. Theoretical Investigation of Some Magnetic and Spectroscopic Properties of Rare-Earth lons. Physical Review, v. 127, n. 6, p. 20582075, 1962.

26 Rivera, V.A.G. et al. Localized Surface Plasmon Resonances: Noble Metal Nanoparticle Interaction with Rare-Earth lons. In: Kim, K. Y. (Ed.): Plasmonics Principles and Applications; Rijeka: IntechOpen, 2012, cap. 11, p. 283-312.

27 McQuarrie, D.A., Simon, J.D. Approximation methods. In : Physical Chemistry A Molecular Approach. Sausalito: University Science Books, 1997, cap. 7 p. 241-273.

28 Goldschmidt, Z.P. Atomic properties (free atom). In : Handbook on the

Physics and Chemistry of Rare Earths. Amsterdam: North-Holland Publishing Company, 1978, cap. 1, p. 1-171.

29 Walsh, B.M. Judd-Ofelt Theory: Principles and Practices . In: Bartolo, B., Forte, O. Advances in Spectroscopy for lasers and sensing. New York: Springer, 2006, cap. 21, p. 403-432.

30 Dieke, G.H. Spectra and energy levels of rare earth ions in crystals. Geneva: Interscience, 1968.

31 Carnall, W.T.; Goodman, G.L.; et al. A systematic analysis of the spectra of the lanthanides doped into single crystal LaF3. The Journal of Chemical Physics, v. 90, n. 7, p. 3443-3457, 1989.

32 Ma, C.G.; Brik, M.G.; et al. Energy level schemes of fN electronic configurations for the di-, tri-, and tetravalent lanthanides and actinides in a free state. Journal of Luminescence, v. 170, p. 369-374, 2016.

33 Atkins, P., et al. d-Metal complexes: electronic structure and properties. In: Shriver \& Atkins Inorganic Chemistry. 5th ed. New York: W. H. Freeman and Company, 2010, cap. 20, p. 473-506. 
34 Lakowicz, J.R. Principles of Fluorescence Spectroscopy. New York: Springer, 2006.

35 Thejo Kalyani, N.; Chitnis, D.; et al. Judd-Ofelt analysis on $\mathrm{pH}$ sensitive $\mathrm{Eu}(\mathrm{tta}) 3$ bipy and $\mathrm{Eu}(\mathrm{dmh}) 3$ phen hybrid organic complexes in various organic solvents for solution processed OLEDs. Materials Science for Energy Technologies, v. 2, n. 3, p. 589-599, 2019.

36 Binnemans, K. Interpretation of europium(III) spectra. Coordination Chemistry Reviews, v. 295, p. 1-45, 2015.

37 Tu, D.; Zheng, W.; et al. Europium-activated luminescent nanoprobes: From fundamentals to bioapplications. Coordination Chemistry Reviews, v. 378, p. 104120, 2019.

38 Harbuzaru, B.V.; Corma, A.; et al. A Miniaturized Linear pH Sensor Based on a Highly Photoluminescent Self-Assembled Europium(III) Metal-Organic Framework. Angewandte Chemie International Edition, v. 48, n. 35, p. 6476-6479, 2009.

39 Zhang, M.; Fan, H.; et al. Synthesis, Characterization, and Luminescence Properties of Uniform Ln3+-Doped YF3Nanospindles. The Journal of Physical Chemistry C, v. 111, n. 18, p. 6652-6657, 2007.

40 Tu, D.; Liu, Y.; et al. Breakdown of crystallographic site symmetry in lanthanidedoped NaYF4 crystals. Angew Chem Int Ed Engl, v. 52, n. 4, p. 1128-1133, 2013.

41 Kalisky, Y. Fluoride Laser Crystals: LiYF4(YLF). In: The physics and engineering of solid state lasers. Bellingham: SPIE - The international Society for Optical Engineering, 2006, cap. 5, p. 43-66.

42 Garcia, E.; Ryan, R.R. Structure of the laser host material LiYF4. Acta Crystallographica Section C Crystal Structure Communications, v. 49, n. 12, p. 2053-2054, 1993.

43 Gorller-Walrand, C.; Binnemans, K.; et al. Crystal-field analysis of Eu3+in LiYF4. Journal of Physics: Condensed Matter, v. 5, n. 44, p. 8359-8374, 1993.

44 Jia, G.; Wang, C.; et al. Local Site Symmetry Determination of Scheelite-Type Structures by Eu3+Spectroscopy. The Journal of Physical Chemistry C, v. 114, n. 41, p. 17905-17913, 2010. 
45 Auzel, F. Upconversion processes in coupled ion systems. Journal of Luminescence, v. 45, n. 1-6, p. 341-345, 1990.

46 Auzel, F. Upconversion and anti-Stokes processes with $f$ and $d$ ions in solids. Chem Rev, v. 104, n. 1, p. 139-173, 2004.

47 Haase, M.; Schafer, H. Upconverting nanoparticles. Angew Chem Int Ed Engl, v. 50, n. 26 , p. 5808-5829, 2011.

48 Zhang, H.; Fu, X.; et al. Photoluminescence of YVO4:Tm phosphor prepared by a polymerizable complex method. Solid State Communications, v. 132, n. 8, p. 527531, 2004.

49 Meijer, M.S.; Rojas-Gutierrez, P.A.; et al. Absolute upconversion quantum yields of blue-emitting LiYF4:Yb(3+), Tm(3+) upconverting nanoparticles. Phys Chem Chem Phys, v. 20, n. 35, p. 22556-22562, 2018.

50 Naccache, R.; Yu, Q.; et al. The Fluoride Host: Nucleation, Growth, and Upconversion of Lanthanide-Doped Nanoparticles. Advanced Optical Materials, v. 3, n. 4, p. 482-509, 2015.

51 Assaaoudi, H.; Shan, G.-B.; et al. Annealing-induced ultra-efficient NIR-to-VIS upconversion of nano-/micro-scale $\alpha$ and $\beta$ NaYF4:Er3+,Yb3+ crystals. CrystEngComm, v. 15, n. 23, 2013.

52 Mai, H.-X.; Zhang, Y.-W.; et al. Size- and Phase-Controlled Synthesis of Monodisperse NaYF4:Yb,Er Nanocrystals from a Unique Delayed Nucleation Pathway Monitored with Upconversion Spectroscopy. The Journal of Physical Chemistry C, v. 111 , n. 37, p. 13730-13739, 2007.

53 Reddy, K.N.; Shareef, M.A.H.; et al. Growth and X-ray study of NaYF4 crystals. Journal of Materials Science Letters, v. 2, n. 2, p. 83-84, 1983.

54 Burns, J.H. Crystal Structure of Hexagonal Sodium Neodymium Fluoride and Related Compounds. Inorganic Chemistry, v. 4, n. 6, p. 881-886, 1965.

55 Wang, F.; Liu, X. Recent advances in the chemistry of lanthanide-doped upconversion nanocrystals. Chem Soc Rev, v. 38, n. 4, p. 976-989, 2009. 
56 Zhang, L.; Wang, Z.; et al. Synthesis of LiYF4:Yb, Er upconversion nanoparticles and its fluorescence properties. J Nanosci Nanotechnol, v. 14, n. 6, p. 4710-4713, 2014.

57 Zhang, Q.; Yan, B. Hydrothermal Synthesis and Characterization of LiREF4 (RE $=\mathrm{Y}, \mathrm{Tb}-\mathrm{Lu})$ Nanocrystals and Their Core-Shell Nanostructures. Inorganic Chemistry, v. 49, n. 15, p. 6834-6839, 2010.

58 Andrade, A.B.; Bispo, G.F.C.; et al. Synthesis and characterization of luminescent Ln3+ ( $\mathrm{Ln}=\mathrm{Eu}, \mathrm{Tb}$ and Dy)-doped LiYF4 microcrystals produced by a facile microwaveassisted hydrothermal method. Journal of Luminescence, v. 219, p. 116843, 2020.

59 Zhang, X.; Wang, M.; et al. Shape-selective synthesis, characterization and upconversion improvement of $\mathrm{Yb3}+/ \mathrm{Er} 3+$ doped LiYF4microphosphors through $\mathrm{pH}$ tuning. RSC Advances, v. 4, n. 55, 2014.

60 Mahalingam, V.; Naccache, R.; et al. Preferential suppression of high-energy upconverted emissions of Tm3+ by Dy3+ ions in Tm3+/Dy3+/Yb3+-doped LiYF4 colloidal nanocrystals. Chem Commun (Camb), v. 47, n. 12, p. 3481-3483, 2011.

61 Mahalingam, V.; Vetrone, F.; et al. Colloidal Tm3+/Yb3+-Doped LiYF4Nanocrystals: Multiple Luminescence Spanning the UV to NIR Regions via LowEnergy Excitation. Advanced Materials, v. 21, n. 40, p. 4025-4028, 2009.

62 Wang, J.; Wang, F.; et al. Lanthanide-doped LiYF4 nanoparticles: Synthesis and multicolor upconversion tuning. Comptes Rendus Chimie, v. 13, n. 6-7, p. 731-736, 2010.

63 Zhang, D.; De, G.; et al. Controlled synthesis and upconversion luminescence properties of LiYF4:Yb0.2Er0.02nanoparticles. Materials Research Express, v. 3, n. 7, 2016.

64 Cheng, T.; Marin, R.; et al. Small and Bright Lithium-Based Upconverting Nanoparticles. J Am Chem Soc, v. 140, n. 40, p. 12890-12899, 2018.

65 Rafique, R.; Baek, S.H.; et al. A facile hydrothermal synthesis of highly luminescent NaYF4:Yb3+/Er3+ upconversion nanoparticles and their biomonitoring capability. Materials Science and Engineering: C, v. 99, p. 1067-1074, 2019. 
66 Kong, W.; Sun, T.; et al. A General Strategy for Ligand Exchange on Upconversion Nanoparticles. Inorg Chem, v. 56, n. 2, p. 872-877, 2017.

67 Palo, E.; Lahtinen, S.; et al. Effective Shielding of $\mathrm{NaYF4:Yb(3+),Er(3+)}$ Upconverting Nanoparticles in Aqueous Environments Using Layer-by-Layer Assembly. Langmuir, v. 34, n. 26, p. 7759-7766, 2018.

68 Bogdan, N.; Vetrone, F.; et al. Carbohydrate-coated lanthanide-doped upconverting nanoparticles for lectin recognition. Journal of Materials Chemistry, v. 20, n. 35, 2010.

69 Kannan, P.; Abdul Rahim, F.; et al. Au nanorod decoration on NaYF(4):Yb/Tm nanoparticles for enhanced emission and wavelength-dependent biomolecular sensing. ACS AppI Mater Interfaces, v. 5, n. 9, p. 3508-3513, 2013.

70 Abdul Jalil, R.; Zhang, Y. Biocompatibility of silica coated NaYF(4) upconversion fluorescent nanocrystals. Biomaterials, v. 29, n. 30, p. 4122-4128, 2008.

71 Gnanasammandhan, M.K.; Idris, N.M.; et al. Near-IR photoactivation using mesoporous silica-coated NaYF4:Yb,Er/Tm upconversion nanoparticles. Nat Protoc, v. 11 , n. 4 , p. $688-713,2016$.

72 Kong, D.; Fan, Y.; et al. Mesoporous silica-coated NaYF4:Yb3+, Er3+ particles for drug release. Journal of Nanoparticle Research, v. 12, n. 2, p. 663-673, 2009.

73 Shan, J.; Ju, Y. Controlled synthesis of lanthanide-doped NaYF4 upconversion nanocrystals via ligand induced crystal phase transition and silica coating. Applied Physics Letters, v. 91, n. 12, 2007.

74 Wei, Z.; Sun, L.; et al. Cysteine modified rare-earth up-converting nanoparticles for in vitro and in vivo bioimaging. Biomaterials, v. 35, n. 1, p. 387-392, 2014.

75 Skripka, A.; Karabanovas, V.; et al. Decoupling Theranostics with Rare Earth Doped Nanoparticles. Advanced Functional Materials, v. 29, n. 12, 2019.

76 Bastos, A.R.N.; Brites, C.D.S.; et al. Thermal Properties of Lipid Bilayers Determined Using Upconversion Nanothermometry. Advanced Functional Materials, v. 29, n. 48, 2019. 
77 Martín-Rodríguez, R.; Meijerink, A. Infrared to near-infrared and visible upconversion mechanisms in LiYF4: Yb3+, Ho3+. Journal of Luminescence, v. 147, p. 147-154, 2014.

78 Hao, S.; Shao, W.; et al. Tuning the size and upconversion emission of NaYF4:Yb3+/Pr3+ nanoparticles through Yb3+ doping. RSC Adv., v. 4, n. 99, p. 56302-56306, 2014.

79 Chen, G.; Ohulchanskyy, T.Y.; et al. Ultrasmall monodisperse $\mathrm{NaYF}(4): \mathrm{Yb}(3+) / \mathrm{Tm}(3+)$ nanocrystals with enhanced near-infrared to near-infrared upconversion photoluminescence. ACS Nano, v. 4, n. 6, p. 3163-3168, 2010.

80 Rojas-Gutierrez, P.A.; DeWolf, C.; et al. Formation of a Supported Lipid Bilayer on Faceted LiYF4:Tm3+/Yb3+Upconversion Nanoparticles. Particle \& Particle Systems Characterization, v. 33, n. 12, p. 865-870, 2016.

81 Chien, H.-W.; Wu, C.-H.; et al. Multiple doping effect of LiYF4:Yb3+/Er3+/Ho3+/Tm3+@LiYF4:Yb3+ core/shell nanoparticles and its application in $\mathrm{Hg} 2+$ sensing detection. Journal of Alloys and Compounds, v. 806, p. 272-282, 2019.

82 Wang, F.; Liu, X. Upconversion multicolor fine-tuning: visible to near-infrared emission from lanthanide-doped NaYF4 nanoparticles. J Am Chem Soc, v. 130, n. 17, p. 5642-5643, 2008.

83 Wang, F.; Liu, X. Multicolor Tuning of Lanthanide-Doped Nanoparticles by Single Wavelength Excitation. Accounts of Chemical Research, v. 47, n. 4, p. 1378-1385, 2014.

84 Wang, F.; Deng, R.; et al. Tuning upconversion through energy migration in coreshell nanoparticles. Nat Mater, v. 10, n. 12, p. 968-973, 2011.

85 Xue, X.; Uechi, S.; et al. Size-dependent upconversion luminescence and quenching mechanism of LiYF_4: $\mathrm{Er}^{\wedge} 3+/ \mathrm{Yb}^{\wedge} 3+$ nanocrystals with oleate ligand adsorbed. Optical Materials Express, v. 3, n. 7, 2013.

86 Shi, Y.; Zhang, F.; et al. Upconversion fluorescence enhancement of NaYF4:Yb/Re nanoparticles by coupling with SiO2 opal photonic crystals. Journal of Materials Science, v. 54, n. 11, p. 8461-8471, 2019. 
87 Rakov, N.; Maciel, G.S. Three-photon upconversion and optical thermometry characterization of Er3+:Yb3+ co-doped yttrium silicate powders. Sensors and Actuators B: Chemical, v. 164, n. 1, p. 96-100, 2012.

88 Suyver, J.F.; Aebischer, A.; et al. Anomalous power dependence of sensitized upconversion luminescence. Physical Review B, v. 71, n. 12, 2005.

89 Pollnau, M.; Gamelin, D.R.; et al. Power dependence of upconversion luminescence in lanthanide and transition-metal-ion systems. Physical Review B, v. 61 , n. 5, p. 3337-3346, 2000.

90 Suyver, J.F.; Aebischer, A.; et al. Novel materials doped with trivalent lanthanides and transition metal ions showing near-infrared to visible photon upconversion. Optical Materials, v. 27, n. 6, p. 1111-1130, 2005.

91 McCabe, K.M.; Hernandez, M. Molecular thermometry. Pediatr Res, v. 67, n. 5, p. 469-475, 2010.

92 Childs, P.R.N.; Greenwood, J.R.; et al. Review of temperature measurement. Review of Scientific Instruments, v. 71, n. 8, p. 2959-2978, 2000.

93 Brites, C.D.S., Millán, A., et al. Lanthanides in Luminescent Thermometry. In: Handbook on the Physics and Chemistry of Rare Earths. Amsterdam: North-Holland Publishing Company, 2016, cap. 281, p. 339-427.

94 Brites, C.D.; Lima, P.P.; et al. Thermometry at the nanoscale. Nanoscale, v. 4, n. 16, p. 4799-4829, 2012.

95 Balabhadra, S.; Debasu, M.L.; et al. Upconverting Nanoparticles Working As Primary Thermometers In Different Media. The Journal of Physical Chemistry C, v. 121, n. 25, p. 13962-13968, 2017.

96 Lojpur, V.; Antic, Z.; et al. Temperature sensing from the emission rise times of $\mathrm{Eu}(3+)$ in SrY2O4. Phys Chem Chem Phys, v. 16, n. 46, p. 25636-25641, 2014.

97 Allison, S.W. A brief history of phosphor thermometry. Measurement Science and Technology, v. 30, n. 7, 2019. 
98 Savchuk, O.A.; Silvestre, O.F.; et al. GFP fluorescence peak fraction analysis based nanothermometer for the assessment of exothermal mitochondria activity in live cells. Sci Rep, v. 9, n. 1, p. 7535, 2019.

99 Tanimoto, R.; Hiraiwa, T.; et al. Detection of Temperature Difference in Neuronal Cells. Sci Rep, v. 6, p. 22071, 2016.

100 Okabe, K.; Inada, N.; et al. Intracellular temperature mapping with a fluorescent polymeric thermometer and fluorescence lifetime imaging microscopy. Nat Commun, v. 3, p. 705, 2012.

101 Aigouy, L.; Tessier, G.; et al. Scanning thermal imaging of microelectronic circuits with a fluorescent nanoprobe. Applied Physics Letters, v. 87, n. 18, 2005.

102 Vetrone, F.; Naccache, R.; et al. Temperature sensing using fluorescent nanothermometers. ACS Nano, v. 4, n. 6, p. 3254-3258, 2010.

103 Bünzli, J.-C.G.; Piguet, C. Taking advantage of luminescent lanthanide ions. Chemical Society Reviews, v. 34, n. 12, p. 1048-1077, 2005.

104 Hemmer, E.; Benayas, A.; et al. Exploiting the biological windows: current perspectives on fluorescent bioprobes emitting above $1000 \mathrm{~nm}$. Nanoscale Horizons, v. 1, n. 3, p. 168-184, 2016.

$105 \mathrm{Li}, \mathrm{X}$; Wei, X.; et al. The emission rise time of BaY2ZnO5:Eu3+ for non-contact luminescence thermometry. Journal of Alloys and Compounds, v. 657, p. 353-357, 2016.

106 Berry, M.T.; May, P.S.; et al. Temperature Dependence of the Eu3+ 5D0 Lifetime in Europium Tris(2,2,6,6-tetramethyl-3,5-heptanedionato). The Journal of Physical Chemistry, v. 100, n. 22, p. 9216-9222, 1996.

107 Souza, A.S.; Nunes, L.A.; et al. Highly-sensitive Eu(3+) ratiometric thermometers based on excited state absorption with predictable calibration. Nanoscale, v. 8, n. 9, p. 5327-5333, 2016.

108 Meert, K.W.; Morozov, V.A.; et al. Energy transfer in $\mathrm{Eu}(3)(+)$ doped scheelites: use as thermographic phosphor. Opt Express, v. 22 Suppl 3, p. A961-72, 2014. 
109 Manzani, D.; Petruci, J.F.; et al. A portable luminescent thermometer based on green up-conversion emission of $\operatorname{Er}(3+) / \mathrm{Yb}(3+)$ co-doped tellurite glass. Sci Rep, v. 7, p. 41596, 2017.

110 Huang, X.; El-Sayed, M.A. Gold nanoparticles: Optical properties and implementations in cancer diagnosis and photothermal therapy. Journal of Advanced Research, v. 1, n. 1, p. 13-28, 2010.

111 Huang, X.; Jain, P.K.; et al. Gold nanoparticles: interesting optical properties and recent applications in cancer diagnostics and therapy. Nanomedicine, v. 2, n. 5, p. 681-693, 2007.

112 Amendola, V.; Pilot, R.; et al. Surface plasmon resonance in gold nanoparticles: a review. Journal of Physics: Condensed Matter, v. 29, n. 20, p. 203002, 2017.

113 Jana, N.R.; Gearheart, L.; et al. Seeding Growth for Size Control of 5-40 nm Diameter Gold Nanoparticles. Langmuir, v. 17, n. 22, p. 6782-6786, 2001.

114 Ziegler, C.; Eychmüller, A. Seeded Growth Synthesis of Uniform Gold Nanoparticles with Diameters of 15-300 nm. The Journal of Physical Chemistry C, v. 115 , n. 11 , p. $4502-4506,2011$.

115 Alex, S.; Tiwari, A. Functionalized Gold Nanoparticles: Synthesis, Properties and Applications--A Review. J Nanosci Nanotechnol, v. 15, n. 3, p. 1869-1894, 2015.

116 Maruyama, T.; Fujimoto, Y.; et al. Synthesis of gold nanoparticles using various amino acids. J Colloid Interface Sci, v. 447, p. 254-257, 2015.

117 Turkevich, J.; Stevenson, P.C.; et al. A study of the nucleation and growth processes in the synthesis of colloidal gold. Discussions of the Faraday Society, v. $11,1951$.

118 Kettemann, F.; Birnbaum, A.; et al. Missing Piece of the Mechanism of the Turkevich Method: The Critical Role of Citrate Protonation. Chemistry of Materials, v. 28 , n. 11 , p. $4072-4081,2016$.

119 Patel, J.; Němcová, L.; et al. Synthesis of surfactant-free electrostatically stabilized gold nanoparticles by plasma-induced liquid chemistry. Nanotechnology, v. 24, n. 24, p. 245604, 2013. 
120 Liu, J.; He, B.; et al. Direct synthesis of hydrogen peroxide from plasma-water interactions. Scientific Reports, v. 6, n. 1, p. 38454, 2016.

121 Govorov, A.O.; Richardson, H.H. Generating heat with metal nanoparticles. Nano Today, v. 2, n. 1, p. 30-38, 2007.

122 Wu, G.; Mikhailovsky, A.; et al. Remotely triggered liposome release by nearinfrared light absorption via hollow gold nanoshells. J Am Chem Soc, v. 130, n. 26, p. 8175-8177, 2008.

123 O'Neal, D.P.; Hirsch, L.R.; et al. Photo-thermal tumor ablation in mice using near infrared-absorbing nanoparticles. Cancer Lett, v. 209, n. 2, p. 171-176, 2004.

124 Rengan, A.K.; Bukhari, A.B.; et al. In vivo analysis of biodegradable liposome gold nanoparticles as efficient agents for photothermal therapy of cancer. Nano Lett, v. 15, n. 2, p. 842-848, 2015.

$125 \mathrm{Hu}, \mathrm{H} . ;$ Yu, M.; et al. Facile Epoxidation Strategy for Producing Amphiphilic UpConverting Rare-Earth Nanophosphors as Biological Labels. Chemistry of Materials, v. 20, n. 22, p. 7003-7009, 2008. 
Capítulo 2 - Caracterização estrutural dos nanocristais de $\mathrm{LiYF}_{4}$ e sua modificação com cisteína 


\section{CARACTERIZAÇÃO ESTRUTURAL DOS NANOCRISTAIS DE LIYF 4 E SUA MODIFICAÇÃO COM CISTEÍNA}

\subsection{Conclusão parcial}

Com a caracterização estrutural das nanopartículas de $\mathrm{LiYF}_{4}$ sintetizadas, foi possível observar que houve reprodutibilidade entre as sínteses. A modificação com cisteína, feita com o objetivo de aumentar a dispersão das partículas em água para possíveis aplicações em meios biológicos, também foi alcançada.

Nas micrografias de MET foi possível observar a formação de losangos em todas as amostras, com tamanho médio equivalente comparando-se todas as amostras. A distribuição de tamanhos mostrou que as amostram possuem uma distribuição estreita de tamanhos, com a Yb20Er2 obtendo uma distribuição mais estreita entre todas as amostras sintetizadas, fato este atribuído ao resfriamento mais eficiente ao final da reação. As imagens de HRMET mostram partículas cristalinas, devido à observação dos planos cristalinos, além da distância entre os planos ser compatível com a distância entre planos (101). Em adição, também foi possível concluir que não houve nenhuma modificação morfológica das partículas após a modificação com cisteína, salvo um maior grau de agregação das partículas. Ainda foi possível observar a cristalinidade e a distância interplanar dos planos (101) após a reação com cisteína.

A DRX mostrou a obtenção da fase tetragonal de LiYF $_{4}$, com a largura dos picos bastante estreita, corroborando com o grau de cristalinidade observada por HRMET. Todas, exceto a Yb3Er0,0025, não apresentaram nenhum pico de difração adicional, permitindo a conclusão de que nenhuma apresenta impurezas maiores ou iguais à $2 \%$. Esta última (Yb3Er0,0025) apresentou picos extras da fase ortorrômbica de $\mathrm{YF}_{3}$, que pela sua intensidade relativa aos picos de $\mathrm{LiYF}_{4}$ concluiu-se que se tratava de uma impureza presente em pequena quantidade. Não houve nenhuma modificação observada nos difratogramas após a modificação com cisteína, confirmando o observado na MET. O tamanho do cristalito foi aproximadamente o mesmo para todas as amostras, e foi possível concluir que se tratam de partículas policristalinas. As exceções para a reprodutibilidade do tamanho do cristalito foram as amostras 
Li300_cys, que apresentou alargamento do pico devido ao porta amostras, e a amostra Yb3Er0,1, que apresentou um tamanho de cristalito ligeiramente menor.

Nos espectros de FTIR foi possível observar bandas de estiramento da ligação $\mathrm{C}-\mathrm{H}, \mathrm{COO}^{-}$e $\mathrm{O}-\mathrm{H}$, todas associadas ao ácido oleico presente na superfície das partículas, este agia como estabilizante do sistema nanométrico. Após a modificação com cisteína, houve a diminuição da intensidade dos estiramentos atribuídos aos grupos $\mathrm{CH}_{2}$, indicando que houve uma reação na insaturação do ácido oleico, com posterior surgimento de bandas atribuídas aos grupamentos $\mathrm{NH}_{3}$ da cisteína, confirmando a modificação da superfície das partículas com cisteína. 
Capítulo 3 - Propriedades espectroscópicas das nanopartículas de $\mathrm{LiYF}_{4}$ dopadas com lantanídeos 


\section{PROPRIEDADES ESPECTROSCÓPICAS DAS NANOPARTÍCULAS DE LIYF 4 DOPADAS COM LANTANÍDEOS}

\subsection{Conclusões parciais}

Utilizando o íon $\mathrm{Eu}^{3+}$ como sonda estrutural, foi possível confirmar a simetria do sítio de coordenação como $\mathrm{S}_{4}$, uma vez que tanto os desdobramentos dos níveis Stark quanto as posições dos picos de emissão são coincidentes com os descritos na literatura. Essa simetria foi confirmada pelos espectros à $12 \mathrm{~K}$, ou seja, não houve alterações na simetria devido à substituição dos íons $\mathrm{Y}^{3+}$ pelos íons $\mathrm{Eu}^{3+}$. Outra característica importante foi a presença de emissão a partir de dois níveis excitados diferentes: $0{ }^{5} \mathrm{D}_{1}$ e $0{ }^{5} \mathrm{D}_{0}$, evidenciando a baixa energia de fônon da matriz. Como esses dois estados excitados estão termicamente acoplados, foi possível utilizá-los como termômetro de intensidade de emissão, como discutido no capítulo 4.

As amostras co-dopadas com íons $\mathrm{Yb}^{3+} \mathrm{e} \mathrm{Er}^{3+}$ apresentaram, sob excitação de laser em $980 \mathrm{~nm}$, as emissões características do íon $\mathrm{Er}^{3+}$. Duas delas na região do verde, próximo aos $550 \mathrm{~nm}\left(\left.{ }^{2} \mathrm{H}_{11 / 2} \rightarrow{ }^{4}\right|_{15 / 2},\left.{ }^{4} S_{13 / 2} \rightarrow{ }^{4}\right|_{15 / 2}\right)$ e uma delas na região do vermelho $\left({ }^{4} \mathrm{~F}_{9 / 2} \rightarrow{ }^{4} I_{15 / 2}\right)$. Existe uma dependência da intensidade dessas bandas em função da concentração dos dopantes, devido à predominância de diferentes mecanismos de excitação por conta da distância entre o íon sensibilizador $\left(\mathrm{Yb}^{3+}\right)$ e o ativador $\left(\mathrm{Er}^{3+}\right)$. Houve ainda um comportamento anômalo na amostra Yb3Er0,025, supondo-se que ocorreu devido à presença de impurezas na matriz. Em todos os casos foi determinado que o processo que envolve a excitação via absorção de dois fótons. Estes resultados foram observados tanto para as nanopartículas em estado sólido quanto dispersas em ciclohexano, portanto, não houve grande influência do solvente nas propriedades espectroscópicas. Por conta disso, pode-se aplicar estes materiais nanoestruturados tanto como sólidos quanto em dispersões hidrofóbicas sem modificação posterior à sua síntese.

As partículas modificadas com cisteína apresentaram se melhor dispersas em água, e neste solvente, as emissões características do íon $\mathrm{Er}^{3+}$ via UC continuaram presentes. Mesmo pela presença de grupamentos $\mathrm{O}-\mathrm{H}$, que são conhecidos supressores de luminescência para os íons lantanídeos, quanto pela atenuação da absorção em $980 \mathrm{~nm}$ pela água utilizada como solvente. A dependência da 
intensidade das transições em $550 \mathrm{~nm}$ e $650 \mathrm{~nm}$ em função da concentração dos dopantes foi menor, possivelmente por conta da absorção da excitação pela água. Conclui-se, portanto, que é possível aplicar estas nanopartículas em dispersão aquosa, desde que modificadas, como neste caso com cisteína. 
Capítulo 4 - Nanopartículas de $\mathrm{LiYF}_{4}$ como termômetros 


\section{NANOPARTÍCULAS DE LIYF 4 COMO TERMÔMETRO}

\subsection{Conclusões parciais}

As nanopartículas de $\mathrm{LiYF}_{4}$ dopadas com $\mathrm{Yb}^{3+}$ e $\mathrm{Er}^{3+}$ exibindo emissão visível a partir da excitação com laser de $980 \mathrm{~nm}$ mostraram-se bons termômetros usando um fator de intensidade $(\Delta)$ definido pela razão de intensidade entre as transições $\left.\left.{ }^{2} H_{11 / 2} \rightarrow{ }^{4}\right|_{15 / 2} \mathrm{e}^{4} S_{13 / 2} \rightarrow{ }^{4}\right|_{15 / 2}$. Vale ressaltar que estes termômetros primários, os quais não necessitam de curvas de calibração; para isso, utiliza-se a equação 11, derivada da equação de Bolztmann. Apenas é necessário calcular os valores de $\Delta \mathrm{E}$ e $\Delta_{0}$ a partir de resultados experimentais.

As partículas tiveram seus $\Delta \mathrm{E}$ calculados a partir do espectro de emissão, deconvolução e calcula de média ponderada. $O \Delta_{0}$ foi obtido a partir da relação linear do fator de intensidade em função da densidade de potência do laser de excitação. De posse desses valores, utilizou-se a equação 11 para calcular a temperatura a partir dos espectros de emissão de conversão ascendente. Dois sistemas foram testados: nanopartículas sem modificação estabilizadas por ácido oleico e dispersas em ciclohexano e nanopartículas modificadas com cisteína dispersas em água.

Ambos os sistemas, em ciclohexano e em água, obtiveram uma resposta linear de $\Delta$ em função da temperatura medida com um termopar imerso na dispersão. Além disso, ao utilizar a equação 11 , verifica-se que o valor de temperatura calculado é bastante próximo ao valor medido, validando assim o uso desses sistemas como termômetros em escala nanométrica. As sensibilidades relativas também foram calculadas e estão condizentes com as descritas na literatura para os dopantes $\mathrm{Yb}^{3+}$ e $\mathrm{Er}^{3+}$.

Um termômetro baseado na emissão down shifting de $\mathrm{Eu}^{3+}$ também foi definido nesse trabalho, utilizando-se a razão entre a intensidade integrada das transições ${ }^{5} \mathrm{D}_{0} \rightarrow{ }^{7} \mathrm{~F}_{1}$ e ${ }^{5} \mathrm{D}_{1} \rightarrow{ }^{7} \mathrm{~F}_{1}$. O $\Delta \mathrm{E}$ entre os estados excitados foi calculado como $1745 \pm 1$ $\mathrm{cm}^{-1}$, comprovando que podem ser utilizados para termometria. Em seguida, observou-se uma supressão da luminescência do $\mathrm{Eu}^{3+}$ em função da temperatura, devido ao aumento de relaxações não radiativas à altas temperaturas. $O$ valor de $\Delta$ mostrou-se quase linear na região estudada, e utilizando-se a distribuição de Boltzmann, notou-se um comportamento linear do gráfico, o que demonstrou sua 
aplicação como termômetro. Os valores de $\mathrm{Sr}$ e $\delta \mathrm{T}$ também foram calculados $(\mathrm{Sr}$ = $2,74 \% . K^{-1}$ e $\delta T=0,12 K$ ) e comparados com valores encontrados na literatura; o termômetro apresentado aqui mostrou-se mais sensível do que os encontrados na literatura e tão preciso quanto os melhores valores apresentados, o que permite concluir que este sistema é um excelente termômetro luminescente na região estudada.

A excitação laser utilizada para se medir os espectros de conversão ascendente foi responsável por um aumento de temperatura nas dispersões, tanto em ciclohexano quanto em água, que foi atribuída tanto à absorção do solvente quanto pela relaxação não radiativa ocorrida nas partículas. Utilizando-se um termopar imerso nas dispersões foi possível observar o perfil de aquecimento em função do tempo para cada uma das dispersões e, utilizando o máximo aquecimento promovido pelo laser, calcular a condutividade térmica das dispersões. Tais valores encontram-se bastante próximos aos valores utilizados para os solventes encontrados na literatura, portanto, a técnica resultou em uma excelente alternativa para obtenção da condutividade térmica desses solventes.

O perfil de aquecimento também foi acompanhado utilizando-se o termômetro luminescente. Os valores de temperatura calculados estão em grande concordância com aqueles medidos com o termopar, e os valores calculados utilizando o termômetro luminescente também permitiu estimar com precisão a condutividade térmica dos solventes. Conclui-se, portanto, que é possível utilizar a termometria luminescente com nanopartículas de $\mathrm{LiYF}_{4}$ para estimar o valor da condutividade térmica dos solventes em que elas estejam dispersas. 
Capítulo 5 - Modificação das nanopartículas de $\mathrm{LiYF}_{4}$ com nanopartículas de ouro e estudo de efeito fototérmico 


\section{MODIFICAÇÃO DAS NANOPARTÍCULAS DE $\mathrm{LIYF}_{4} \quad$ COM NANOPARTÍCULAS DE OURO E ESTUDO DE EFEITO FOFOTÉRMICO.}

\subsection{Conclusões parciais}

A caracterização estrutural dos nanocristais de $\mathrm{LiYF}_{4}$ modificados com nanopartículas de ouro se mostrou um sucesso. A DRX não mostrou nenhuma alteração nos picos de difração da matriz de fluoreto, entretanto, houve o surgimento de um pico associado à fase cúbica de ouro. As imagens de MET mostrou pontos de maior contraste que foram atribuídas à presença das nanopartículas de ouro, e confirmadas por meio do contraste Z e mapeamento por EDS. No FTIR foi observada a supressão das bandas atribuídas às ligações $\mathrm{N}-\mathrm{H}$, o que permitiu concluir que as interações entre as nanopartículas e o ouro se davam pelo grupamento amina contido na cisteína.

Utilizando o espectro de absorção na região do visível da suspensão das nanopartículas de ouro, foi possível estimar o seu diâmetro e o número de partículas adicionadas à suspensão de LiYF4. Notou-se uma discrepância entre o obtido por MET e pelo espectro de absorção, atribuído à uma agregação das nanopartículas de ouro. O número de nanopartículas de ouro adicionada foi 10 ordens de grandeza menor do que o número de partículas na suspensão de $\mathrm{LiYF}_{4}$.

Havia também uma grande sobreposição entre a emissão do $\mathrm{Er}^{3+} \mathrm{e}$ a absorção das nanopartículas de ouro, o que permitiu a hipótese da geração de aquecimento para tratamento fototérmico, entretanto, não foi possível observar um aumento de temperatura sob excitação de $980 \mathrm{~nm}$. Uma hipótese levantada para que não houvesse aquecimento é o número muito menor de nanopartículas de ouro, o que impossibilitou a transferência efetiva de energia de maneira a contribuir para um aumento de temperatura. 


\section{$\diamond$ Conclusão geral}

Neste trabalho foi abordada a síntese, caracterização e modificação de nanopartículas de $\mathrm{LiYF}_{4}$ dopadas com íons lantanídeos. O método de síntese escolhido foi a decomposição térmica de trifluoroacetatos, que rendeu nanopartículas em formato de losango com dimensões de aproximadamente $80 \times 50 \mathrm{~nm}$, que apresentaram a fase cristalina tetragonal com tamanho de cristalito de aproximadamente $20 \mathrm{~nm}$. A espectroscopia FTIR permitiu concluir que as partículas obtidas possuíam em sua superfície o ácido oleico, que atuou como estabilizador estérico para esses nanomateriais, conferindo dispersão dessas partículas somente em solventes apolares, como ciclohexano. Em seguida, foi feita uma modificação com cisteína na superfície dessas partículas, a partir da epoxidação do ácido oleico e abertura do anel epóxido pela cisteína. Essa modificação não alterou as características morfológicas das partículas, como tamanho e formato, da mesma forma em que não alterou as propriedades cristalinas (fase cristalina e tamanho de cristalito), entretanto, por espectroscopia FTIR, foi possível confirmar o surgimento de bandas associadas à ligações $\mathrm{N}-\mathrm{H}$, evidenciando não só o sucesso na modificação, como um indicativo que a abertura do anel epóxido se deu pelo grupamento tiol da cisteína. Essa modificação permitiu que as nanopartículas fossem dispersas em água.

Tais partículas foram dopadas com o íon $\mathrm{Eu}^{3+}$ ou codopadas com o par $\mathrm{Yb}^{3+} \mathrm{e}$ $\mathrm{Er}^{3+}$ com o objetivo de se estudar as propriedades espectroscópicas de downshifting e conversão ascendente de energia, respectivamente. A luminescência de $\mathrm{Eu}^{3+}$ por downshifting permitiu concluir que há a ocupação de apenas um sítio de simetria que, de acordo com as observações da emissão em alta resolução, apresentou simetria $S_{4}$. Foi possível observar emissões oriundas de dois estados excitados diferentes, o ${ }^{5} D_{1}$ e ${ }^{5} D_{0}$, que permitiram concluir que a energia de fônon da matriz de fato é baixa, uma vez que o decaimento não radiativo entre esses dois estados excitados não foi completo. Os tempos de vida do estado excitado foram calculados, sendo 9,43 ms para $0{ }^{5} \mathrm{D}_{0}$ e $1,65 \mathrm{~ms}$ para $0{ }^{5} \mathrm{D}_{1}$, mostrando que há um grande decaimento não radiativo do ${ }^{5} D_{1}$ para $0{ }^{5} D_{0}$. À temperaturas criogênicas, esses tempos de vida se tornaram bastante próximos $\left(7,94 \mathrm{~ms}\right.$ para o ${ }^{5} \mathrm{D}_{0}$ e $7,62 \mathrm{~ms}$ para $\left.0{ }^{5} \mathrm{D}_{1}\right)$, uma vez que o decaimento não radiativo foi suprimido. 
Já a emissão por conversão ascendente de energia utilizando o par $\mathrm{Yb}^{3+} \mathrm{e} \mathrm{Er}^{3+}$ foi feita com excitação em $980 \mathrm{~nm}$. Foi possível observar duas regiões de emissão, uma no verde $(\lambda \approx 550 \mathrm{~nm})$, atribuída às transições $\left.{ }^{2} \mathrm{H}_{11 / 2} \rightarrow{ }^{4}\right|_{15 / 2} \mathrm{e}{ }^{4} S_{13 / 2} \rightarrow{ }^{4} I_{15 / 2}$, e outra na região do vermelho $(\lambda \approx 650 \mathrm{~nm})$, atribuída à transição $\left.{ }^{4} \mathrm{~F}_{9 / 2} \rightarrow{ }^{4}\right|_{15 / 2}$ do íon $\mathrm{Er}^{3+}$. Por possuir uma seção de choque maior e estado excitado ressonante à estados excitados do $\mathrm{Er}^{3+}$, o íon $\mathrm{Yb}^{3+}$ serviu como sensibilizador da luminescência pelo mecanismo ETU. Variando-se a potência do laser, foi observado um aumento exponencial da intensidade, que permitiu concluir que dois fótons estavam envolvidos em ambas as emissões. Essas observações foram feitas tanto para a amostra em estado sólido, quanto para as amostras dispersas em ciclohexano e água. Apesar de a água ser conhecida como supressor de luminescência por decaimentos não radiativos e também absorver na região de $980 \mathrm{~nm}$, a única mudança ocorrida foi uma menor intensidade de emissão, com os processos de conversão ascendente de energia ainda envolvendo dois fótons.

Em seguida, as propriedades espectroscópicas desses materiais foram exploradas como sensores de temperatura. $\mathrm{O}$ íon $\mathrm{Er}^{3+}$ possui dois estados excitados que são chamados termicamente acoplados, ou seja, sua população relativa e, portanto, sua intensidade é dependente da temperatura do meio em que se encontram. Tais níveis são responsáveis pela emissão na região de $550 \mathrm{~nm}$, ou seja, os níveis são $0{ }^{2} \mathrm{H}_{11 / 2}$ e $0{ }^{4} S_{13 / 2}$. Foram feitos espectros de emissão de conversão ascendente de energia em diferentes temperaturas e utilizando uma equação derivada da lei de distribuição de Boltzmann, foi possível calcular a temperatura do meio a partir do espectro de emissão do íon $\mathrm{Er}^{3+}$ sob excitação em $980 \mathrm{~nm}$. Portanto, a conversão ascendente de energia do $\mathrm{Er}^{3+}$ funcionou como um termômetro primário (sem a necessidade de uma curva de calibração). A sensibilidade térmica relativa do termômetro descrito neste trabalho está próxima à encontrada para o mesmo íon na literatura, enquanto a incerteza na temperatura foi ligeiramente maior, devido à relação sinal-ruído não ter sido otimizada apropriadamente. Tanto as amostras dispersas em ciclohexano como em água foram capazes de obter bons resultados no cálculo da temperatura.

Os estados excitados ${ }^{5} D_{1}$ e ${ }^{5} D_{0}$ do íon $E^{3+}$ também são termicamente acoplados, portanto foram escolhidas as emissões ${ }^{5} \mathrm{D}_{0} \rightarrow{ }^{7} \mathrm{~F}_{1} \mathrm{e}^{5} \mathrm{D}_{1} \rightarrow{ }^{7} \mathrm{~F}_{1}$ para ser um termômetro. Houve uma supressão da luminescência com o aumento da temperatura, 
devido à um aumento nas perdas de energia não radiativas no sistema. A razão entre essas intensidades possuiu boa resposta com a variação da temperatura utilizando uma equação de distribuição de Boltzmann, que tornou possível o cálculo da temperatura a partir da emissão do $\mathrm{Eu}^{3+}$. O termômetro luminescente de $\mathrm{Eu}^{3+}$ descrito neste trabalho apresentou um valor de sensibilidade térmica relativa maior do que exemplos encontrados na literatura e valores de incerteza de temperatura menores, indicando ser um excelente material para aplicações termométricas.

Como exemplo de aplicação dos termômetros luminescentes por conversão ascendente de energia, eles foram utilizados para o cálculo da condutividade térmica das dispersões de nanopartículas. Em primeiro lugar, a condutividade térmica foi obtida a partir dos dados medidos por um termopar imerso nas suspensões (em ciclohexano ou em água), cujos valores obtidos foram iguais aos encontrados na literatura para os solventes utilizados. Em seguida, utilizando o cálculo da temperatura com os termômetros luminescentes por conversão ascendente de energia do íon $\mathrm{Er}^{3+}$, foram calculados os valores da condutividade térmica dos solventes, onde novamente foram obtidos valores iguais aos encontrados na literatura para os solventes. Dessa maneira, foi validado o cálculo da condutividade térmica a partir da termometria luminescente.

Por fim, as nanopartículas modificadas com cisteína foram funcionalizadas com nanopartículas de ouro, a fim de se estudar as propriedades fototérmicas do sistema. Foram utilizadas duas funcionalizações diferentes: a primeira pela síntese in situ das nanopartículas de ouro por aplicação de plasma de He e a segunda pela simples mistura das nanopartículas modificadas com cisteína e nanopartículas de ouro sintetizadas pelo método de Turkevich sob agitação.

No primeiro caso, o plasma foi responsável pela produção de espécies redutoras em uma suspensão de nanopartículas de $\mathrm{LiYF}_{4}$ dopadas com Eu ${ }^{3+}$, formando nanopartículas de ouro, como pôde ser observado a olho nu. O máximo de absorção na região do visível foi compatível com a formação das nanopartículas de ouro de aproximadamente $70 \mathrm{~nm}$, o que foi confirmado por microscopia eletrônica de transmissão. A difração de raios $X$ não mostrou nenhuma modificação na estrutura cristalina do $\mathrm{LiYF}_{4}$, entretanto, atestou a formação da fase cúbica de ouro. $\mathrm{Na}$ luminescência do íon $\mathrm{Eu}^{3+}$ não foram obsevadas mudanças nas posições ou na largura das bandas, contudo, a razão entre o sinal e o ruído do espectro teve uma 
diminuição considerável na presença de ouro, levando a crer que houve uma supressão por conta de transições não radiativas.

Para se estudar um possível efeito fototérmico, nanopartículas de ouro foram sintetizadas por método Turkevich e misturadas sob agitação magnética. A supressão das bandas atribuídas às ligações $\mathrm{N}-\mathrm{H}$ no espectro de FTIR indicou que pode haver uma interação entre as nanopartículas de ouro com a superfície das partículas de $\mathrm{LiYF}_{4}$ por meio dos grupos amina presentes na cisteína. As imagens da microscopia eletrônica de transmissão em alta resolução no modo escuro, juntamente com o modo contraste $Z$ e mapeamento por EDS mostraram a presença de nanopartículas de ouro na superfície das partículas de $\mathrm{LiYF}_{4}$. Em seguida, foi medida a taxa de aquecimento máximo com a incidência do laser de excitação em 980 nm, que não mostrou nenhum efeito fototérmico. 


\section{$\diamond$ Perspectivas}

Neste trabalho, foram explorados termômetros luminescentes baseados em $\mathrm{LiYF}_{4}$ dopados com íons lantanídeos tanto em seu estado sólido, no caso das partículas dopadas com $\mathrm{Eu}^{3+}$, como em dispersões em solventes orgânicos e dispersões aquosas, utilizando o par $\mathrm{Yb}^{3+} / \mathrm{Er}^{3+}$ como dopantes.

O termômetro luminescente baseado na razão entre as emissões oriundas dos estados excitados ${ }^{5} D_{1}$ e ${ }^{5} D_{0}$ podem ser utilizados, por exemplo, revestimentos funcionais em peças de grande interesse industrial, cujo estresse térmico necessite ser definido. Para isso, são necessários estudos adicionais para se discutir os melhores dispersantes para essa matriz, assim como os limites de temperatura que podem ser utilizados para essa técnica. Desse modo, os resultados apresentados aqui servem como uma excelente prova de conceito, necessitando um ligeiro aprofundamento dos estudos para que esse material possa ser amplamente aplicado.

Já os termômetros baseados na conversão ascendente do par $\mathrm{Yb}^{3+} / \mathrm{Er}^{3+}$ mostrou-se útil para se estimar a condutividade térmica de solventes. Portando, esse tipo de material pode ser amplamente aplicado com essa finalidade, uma vez que outros métodos possuem algumas desvantagens citadas, como custo e erros intrínsecos. Entretanto, ainda há espaço para otimização desse sistema, uma vez que os valores de incertezas na temperatura calculados possuem um valor elevado. Portanto, são necessários estudos posteriores para encontrar a concentração ideal tanto da dispersão de nanopartículas em si, quanto de dopantes no material em si.

Apesar do resultado negativo na geração de calor com a transferência de energia da emissão do $\mathrm{Er}^{3+}$ para nanopartículas de ouro, ainda se acredita que este efeito seja possível. Um dos possíveis parâmetros a serem alterados é a quantidade de nanopartículas de ouro em relação às nanopartículas luminescentes. Alternativamente, modificações na superfície das nanopartículas de $\mathrm{LiYF}_{4}$ de maneira a possibilitar ligações covalentes entre elas e as nanopartículas de ouro podem ser uma alternativa viável para observar o fenômeno desejado.

Portanto, essa tese abre diversas possibilidades futuras, tanto para materiais aplicados quanto para estudos de ciência básica envolvendo transferência de energia. 